\title{
Modelling viscosity of liquid dropout near wellbore region in gas condensate reservoirs using modern numerical approaches.
}

F.Faraji, J.O.Ugwu, P.L. Chong, F. Nabhani

School of Science, Engineering and Design, Teesside University, Middlesbrough, TS1 3BA, UK

\section{Abstract}

7 Liquid dropout occurs in gas condensate reservoirs below the dew point pressure around near wellbore region as a result of depletion from production of such reservoirs. Forecasting production as well as optimizing future recoveries of gas condensate reservoirs are highly desirable. This is not possible to achieve without accurate determination of liquid dropout viscosity $\left(\mu_{c}\right)$ below the dew point. The focus of research in past decades has been on the development of accurate viscosity prediction models below the dew point pressure to ensure accurate condensate production forecast. Gas condensate production forecast and optimisation around this region and condition are complicated due to unique gas condensate behaviour that violates thermodynamic laws.

Current methods are based on correlation estimation, however the accuracy of these correlations are less than satisfactory, and root cause is due to the miscapturing of complex behaviour of gas condensate reservoir near the wellbore region. These motivated the consideration of modern numerical approaches such as the Least Square Support Vector Machine (LSSVM) and Artificial Neural Network (ANN) used in this paper. These methods are considered as more data behaviour oriented, with the capability of capturing the fluid complexity of gas condensate in such conditions.

In this study viscosity of condensate phase near the wellbore region was modelled using machine learning techniques including ANN and LSSVM. For this purpose, over 300 viscosity data sets were collected from published literature and experimental studies worldwide. This databank includes API gravity, reservoir temperature, solution gas to oil ratio (Rs), specific gas gravity, fluid compositions and reservoir pressure.

Six well known previously published viscosity correlations refined using least-square approach to match the experimental data. Qualitative and quantitative error analysis of developed LSSVM and ANN showed their performance superiority over refined literature correlations. The new proposed models can be embedded as an extra feature of commercial reservoir simulation packages for optimization and future recoveries of gas condensate reservoirs.

Keywords:

35 Condensate viscosity, Gas condensate, Machine Learning (ML), Least Square Support Vector Machine (LSSVM), Artificial Neural network (ANN), Correlations 


$\begin{array}{lll}38 & \text { Nomenclature and units } \\ 39 & & \text { Oil API gravity } \\ 40 & \text { API } & \text { Artificial Neural Network } \\ 41 & \text { ANN } & \text { Least Square Support Vector Machine } \\ 42 & \text { LSSVM } & \text { Machine Learning } \\ 43 & \text { ML } & \text { Root Mean Square Error } \\ 44 & \text { RMSE } & \text { Gas to oil Ratio (scf/STB) } \\ 45 & \text { GOR } & \text { Solution gas to oil ratio (scf/STB) } \\ 46 & \text { Rs } & \text { Dead oil viscosity (cp) } \\ 47 & \mu_{d} & \text { Live oil viscosity (cp) } \\ 48 & \mu_{o b} & \text { Condensate viscosity (cp) } \\ 49 & \mu_{c} & \text { High pressure high temperature } \\ 50 & \text { HPHT } & \text { Number of data points } \\ 51 & \text { N } & \text { Reservoir pressure (psia) } \\ 52 & \mathrm{P} & \left.\text { Temperature ( }{ }^{\circ} \mathrm{F}\right) \\ 53 & \mathrm{~T} & \text { Centipoise } \\ 54 & \mathrm{cp} & \\ & & \end{array}$

\section{1. Introduction}

56 As reservoir pressure reduces in gas condensate to below the dew point due to 57 production, the liquid evolved from gas phase and creates multi-phase flow near the 58 wellbore region. Accumulation of the liquid in aforementioned region is increasing with 59 time and is usually very high in rich gas condensate reservoirs. This phenomenon is 60 called "liquid banking" and can cause severe productivity declines (Wheaton and 61 Zhang, 2007). To understand this complex behaviour in depleting gas condensate 62 reservoirs for forecasting production and optimizing future recoveries viscosity 63 determination of the condensate liquid below the dew point is essential (Audonnet and 64 Pádua, 2004; Kashefi et al., 2013).

65 In fact, inaccurate estimation of condensate liquid viscosity below the dew point has 66 detrimental effect on cumulative production and can lead to large errors in reservoir 67 performance. Previous studies show $1 \%$ error in reservoir fluid viscosity resulted in a $681 \%$ error in cumulative production (Al-Meshari et al., 2007; Whitson et al., 1999; Yang 69 et al., 2007).

70 Measurement of condensate viscosity in gas condensate reservoirs is not made in a 71 routine laboratory test and it may be very difficult to obtain due to unavailability of the 72 samples, lack of high pressure high temperature (HPHT) facilities, small volume cell 
viscometers and time and cost required for the measurements. Consequently this

74 makes use of theoretical correlation more attractive (Al-Meshari et al., 2007; Hemmati-

75 Sarapardeh et al., 2014; Whitson et al., 1999).

76 Depending on the input variables the correlations can be divided to two classes: 1). 77 semi-empirical models that use reservoir fluid composition, critical temperature, 78 acentric factor, pour point temperature, molar mass and boiling point. 2). the 79 correlations which use field data such as reservoir temperature, pressure, API gravity 80 and solution gas to oil ratio "Rs" (Chew and Connally, 1959; Khan et al., 1987). These correlations are deployed for three different conditions of under saturated, saturated and dead oil viscosity.

83 Condensate liquid viscosity is typically low for depleted gas condensate reservoirs, 84 ranging from 0.1 to $1 \mathrm{cp}$, in the near wellbore region (Al-Nasser and Al-Marhoun, 2012; 85 Whitson et al., 1999). The API gravity of condensate reservoirs are between 40 to $60^{\circ} \mathrm{API}$ with gas to oil ratio (GOR) between $3000-150000$ scf/STB and temperature between critical temperature $\left(127^{\circ} \mathrm{C}\right)$ and cricondentherm temperature $\left(250^{\circ} \mathrm{C}\right)$ (Ahmed, 2010; Whitson et al., 2000). The above conditions were our constraint in selecting existing literature viscosity correlations for this study. Variation of the condensate viscosity with reservoir composition is estimated using the correlation proposed by Lohrenz et al., (1964). This correlation is the most widely used viscosity model, especially in many commercial compositional simulators (ECLIPSE, 2014). Lohrenz et al., (1964), known commonly as LBC, is developed for predicting viscosity of dense gas mixture based on the original work of Jossi et al., (1962) for pure substances using corresponding state principle. Prediction performance of LBC model for viscosity prediction of gas phase in gas condensate reservoirs is reasonable, while prediction of condensate liquid viscosity by this method is very poor (Yang et al., 2007). Consequently, it is necessary to tune the LBC correlation by adjusting its coefficients to match the experimental data. This method is selected because it is taking into account compositional changes based on reduced density, which is characteristic of gas condensate reservoirs below the dew point (Fevang and Whitson, 1996; Mott, 2003).

103 Gas-saturated-oil (live oil) viscosity correlations are another alternative in literature 104 that can be used to determine the condensate oil viscosity. Yang et al., (2007) 105 suggested to use live oil $\left(\mu_{o b}\right)$ viscosity correlations to predict condensate liquid 106 viscosity if the measured data is not available. These correlations are function of 
107

108

109

110

111

112

113

114

115

116

117

118

119

120

121

122

123

124

125

126

127

128

129

130

131

132

133

134

135

136

137

138

139

140

solution gas to oil ratio Rs, reservoir pressure, reservoir temperature, fluid API gravity and gas specific gravity $\left(\gamma_{G a s}\right)$. Subsequently these parameters are classed as input variables for developing our ANN and LSSVM models (Fig. 5). Rs is often the most significant component of the PVT correlations, which have big influence on the oil viscosity and should be precisely measured in any selected correlations (HemmatiSarapardeh et al., 2014). The solution gas to oil ratio is the amount of gas dissolved in the oil at any pressure. It increases linearly with pressure and it is a function of reservoir fluid composition (Fevang and Whitson, 1996; Jokhio et al., 2002).

The commonly used literature correlations for estimating gas-saturated-oil viscosities and comply with our defined constrained mentioned earlier are Beggs and Robinson, (1975), Kartoatmodjo and Schmidt, (1991), De Ghetto et al., (1994), Elsharkawy and Alikhan, (1999) and Bergman, (2000). The detailed formula of each correlation is given in Table 3. Further description of each correlation include their advantage and disadvantage is given in Appendix 1. These empirical correlations are used to estimate gas-saturated-oil viscosity as a direct function of dead oil viscosity. A brief discussion of each correlation is presented in following.

Beggs and Robinsons, (1975) developed a live oil viscosity correlation based on 2073 observations. The average error of $-1.83 \%$ have been recorded during testing for proposed correlation. Their correlation is covering solution gas to oil ratio (Rs) within the range of 20 to $2070 \mathrm{scf} / \mathrm{STB}$, oil gravity of 16 to $58^{\circ} \mathrm{API}$, pressure range of 0 to 5250 and temperature of 70 to $295^{\circ} \mathrm{F}$ (Beggs and Robinson, 1975; El Aily et al., 2019).

Using 5321 gas-saturated-oil samples collected globally Kartoatmodjo and Schmidt, (1991) developed a gas-saturated-oil viscosity correlation as a function of dead oil viscosity and Rs. Their correlation can be applied for crude oils in the range of 14.4 to $59^{\circ} \mathrm{API}$ gravity, temperature range of 80 to $320^{\circ} \mathrm{F}$, Rs range of 0 to 2890 scf/STB and live oil viscosity range of 0.098 to $586 \mathrm{cp}$ (Kartoatmodjo and Schmidt, 1991).

De Ghetto et al., (1994) developed a correlation for light oil viscosity with gravity of API > 31.1 as a function of solution gas to oil ratio (Rs) and dead oil viscosity. His correlation is based on 195 data points collected globally. Their correlation is able to predicts live oil viscosity with less than $10 \%$ error within the temperature range of 80.6 to $334.6{ }^{\circ} \mathrm{F}$, Rs of 8.61 to $3299 \mathrm{scf} / \mathrm{STB}$ and $0.07<\mu_{o b}<295.9 \mathrm{cp}$ (De Ghetto et al., 1994). 
141 Elsharkawy and Alikhan, (1999) developed their gas-saturated-oil viscosity correlation

142 utilizing 254 datasets from Middle East oil samples. They concluded their research

143 with $18.6 \%$ average absolute relative error obtained from proposed correlation. Their 144 correlation covers the data range of 10 to 3600 for (Rs) and 0.05 to $20.89 \mathrm{cp}\left(\mu_{o b}\right)$

145 (Elsharkawy and Alikhan, 1999).

146 Bergman, (2000) developed a gas-saturated crude oil viscosity using 2048 data points 147 collected from worldwide. Bergman's correlation can be used in the range of 5 to 1482890 scf/STB solution gas to oil ratio (Rs) and live oil viscosity $\left(\mu_{o b}\right)$ range of 0.125 to $149123 \mathrm{cp}$ with absolute average error of $9 \%$ (Whitson et al., 2000).

150 All aforementioned correlations developed from crude oil, which has compositional 151 differences with gas condensate fluid composition. Moreover, they are direct function 152 of dead oil viscosity, which is one of the most unreliable properties to be predicted by 153 correlations due to the large effect that oil type (paraffinicity, aromaticity and 154 asphaltene content) has on viscosity (Aily et al., 2019; Whitson et al., 2000). 155 Condensate liquid viscosity in near wellbore region can change significantly during 156 depletion in gas condensate reservoirs (Al-Meshari et al., 2007; Fevang, 1995; 157 Whitson et al., 2000). Consequently, empirical and semi-empirical correlations do not 158 fully reflect the viscosity changes with pressure in gas condensate reservoirs near 159 wellbore region. Therefore, the utilized correlations in this study have tuned to match 160 the experimental condensate liquid viscosity data.

161 The recent development and success of machine learning techniques in solving 162 complex engineering problems has drawn attention to their various application in petroleum industry (Ahmadi et al., 2014; Ahmadi and Ebadi, 2014a; Ghiasi et al., 2014; Hemmati-Sarapardeh et al., 2014; Kamari et al., 2013; Naderi and Khamehchi, 2019; Shokir, 2008). For gas condensate reservoirs Ahmadi and Ebadi (2014), Elsharkawy 166 and Foda (1998), Jalali et al. (2007) and Nowroozi et al. (2009) were using machine learning (ML) approach for predicting dew point pressure. Zendehboudi et al. (2012) used ML approach to model condensate-to-gas ratio (CGR) of gas condensate reservoirs. Recently Ghiasi et al. (2014) employed LSSVM to predict compressibility factor of gas condensate reservoirs.

171 Although the aforementioned studies modelled some aspects of gas condensate 172 reservoirs such as dew point pressure, CGR and compressibility factor, however there 173 is a gap in literature for modelling viscosity of gas condensate reservoirs using ML 174 approaches. In fact, to the best of the author's knowledge, there is not any published 
175 work on modelling condensate liquid viscosity of gas condensate reservoirs using any 176 ML approach. Therefore, the aim of this study is to develop novel models for prediction 177 of condensate viscosity in gas condensate reservoirs based on machine learning 178 techniques, namely, Least Squares Support Vector Machine (LSSVM) and Artificial 179 Neural Network (ANN). For this purpose, more than 300 data sets from 13 PVT reports 180 and experimental study were collected and a data bank was created. To establish 181 accuracy of the proposed models an error analysis in terms of coefficient of 182 determination $\left(\mathrm{R}^{2}\right)$, root-mean square error (RMSE) and mean square error (MSE) is 183 carried out. In addition, in order to evaluate the performance of the newly proposed 184 models against the existing empirical correlations, graphical and statistical error 185 analysis are utilized (Hagan and Menhaj, 1994).

\section{2. Methodology}

\subsection{Data acquisition}

188 A database was developed in order to ascertain the accuracy of the proposed methods 189 and examine the suitability of published viscosity correlations. Data from gas 190 condensate PVT reports and also experimental investigation of gas condensate fluid 191 is the base of our data bank. More than 300 data sets have been utilized for developing 192 and testing the models. This data bank includes API gravity, gas specific gravity, 193 reservoir fluid compositions, reservoir pressure, reservoir temperature and initial gas 194 to oil ratio (GOR). Various techniques were used to measure viscosity of the 195 condensate phase such as using electromagnetic pulse technology viscometer, rolling 196 ball viscometer and capillary viscometer.

197 Ranges, sources and their corresponding statistical parameters of the data are 198 presented in Table 1. The data base represents a comprehensive wide range of gas 199 condensate systems obtained worldwide. Hence, the developed models in this study 200 should be reliable to use in prediction of condensate viscosity below the dew points 201 globally within the specified pressure and temperature.

\begin{tabular}{|l|c|c|c|c|c|}
\hline Author & $\begin{array}{c}\text { Source of } \\
\text { data }\end{array}$ & Pressure(psia) & Tem ( ${ }^{\circ}$ F) & $\begin{array}{l}\text { Solution } \\
\text { GOR(Rs) }\end{array}$ & $\boldsymbol{\mu ( \mathbf { c p } )}$ \\
\hline $\begin{array}{l}\text { Al-Meshari et } \\
\text { al., (2007) }\end{array}$ & $\begin{array}{c}\text { Saudi } \\
\text { Arabia }\end{array}$ & $0-5000$ & 243 & $334-6759$ & $0.264-$ \\
Yang et al., & Norway & $630-7014$ & 338 & $1889-10279$ & 0.561 \\
$(2007)$ & & & & & $0.178-$ \\
\hline
\end{tabular}




\begin{tabular}{|c|c|c|c|c|c|}
\hline $\begin{array}{l}\text { Kashefi et al., } \\
(2013)\end{array}$ & $\begin{array}{l}\text { Binary } \\
\text { Mixture }\end{array}$ & $6011-20023$ & $122-302$ & $8125-25067$ & $\begin{array}{c}0.034- \\
0.199\end{array}$ \\
\hline $\begin{array}{l}\text { Thomas and } \\
\text { Bennion, } \\
(2009)\end{array}$ & $\begin{array}{l}\text { Recombined } \\
\text { fluid }\end{array}$ & $2900-10600$ & 246 & $2985-11812$ & $\begin{array}{c}0.076- \\
0.62\end{array}$ \\
\hline $\begin{array}{l}\text { Chen et al., } \\
(1995)\end{array}$ & North Sea & $4520-5733$ & 259 & $7195-9264$ & $\begin{array}{c}0.1175- \\
0.1572\end{array}$ \\
\hline $\begin{array}{l}\text { Wheaton and } \\
\text { Zhang, (2007) }\end{array}$ & $\begin{array}{l}\text { Mixture C1- } \\
\text { C7 }\end{array}$ & $304-2393$ & 160 & $283-2661$ & $\begin{array}{l}0.04- \\
0.141\end{array}$ \\
\hline $\begin{array}{l}\text { Saeedi and } \\
\text { Rowe, (1981) }\end{array}$ & US & $253-2730$ & $109-189$ & $1889-10279$ & $\begin{array}{c}0.171- \\
0.271\end{array}$ \\
\hline $\begin{array}{l}\text { Gozalpour et } \\
\text { al., (2005) }\end{array}$ & $\begin{array}{l}\text { Binary } \\
\text { Mixture }\end{array}$ & $549-5019$ & 100 & $6859-8592$ & $\begin{array}{c}0.0386- \\
0.042\end{array}$ \\
\hline $\begin{array}{l}\text { Guo et al., } \\
\text { (1997) }\end{array}$ & $\begin{array}{l}\text { Binary } \\
\text { Mixture }\end{array}$ & $2610-5366$ & $110-262$ & $5551-6000$ & $0.45-0.67$ \\
\hline $\begin{array}{l}\text { O'Dell and } \\
\text { Miller, (1967) }\end{array}$ & US, Texas & $1500-3500$ & Unknown & $2027-4731$ & $\begin{array}{c}0.075- \\
0.27\end{array}$ \\
\hline $\begin{array}{l}\text { Fetkovich et } \\
\text { al., (1986) }\end{array}$ & North Sea & $2827-6791$ & 155 & $3686-9180$ & $\begin{array}{c}0.171- \\
0.332\end{array}$ \\
\hline $\begin{array}{l}\text { Ghahri et al., } \\
(2011)\end{array}$ & Binary Fluid & $800-5255$ & Unknown & $1081-7103$ & $\begin{array}{c}0.0261- \\
0.1411\end{array}$ \\
\hline $\begin{array}{l}\text { Audonnet and } \\
\text { Pádua, (2004) }\end{array}$ & Binary Fluid & $14-10877$ & $76-247$ & $18-14703$ & $\begin{array}{c}0.086- \\
1.672\end{array}$ \\
\hline
\end{tabular}

Table 1. The origin and the ranges of data used for condensate liquid viscosity study.

2032.2 Prediction of liquid dropout viscosity using literature correlations

204 The (Lohrenz et al., 1964) correlation shown in Eq. (1) is one of the most common 205 methods in petroleum industry for estimating the viscosity of petroleum fluid and 
206 commonly known as LBC method. The LBC is based on generalised relationship 207 between viscosity and fourth degree polynomial of the reduced density.

$$
\begin{gathered}
{\left[\left(\mu-\mu^{*}\right) \zeta+10^{-4}\right]^{\frac{1}{4}}=A_{0}+A_{1} \rho_{r}+A_{2} \rho_{r}{ }^{2}-} \\
A_{3} \rho_{r}{ }^{3}+A_{4} \rho_{r}{ }^{4}
\end{gathered}
$$

208 Where $\zeta$ is the viscosity reducing parameter shown in Eq. (2), $\rho_{p r}$ is reduced density 209 calculated by Eq. (3), $\mu^{*}$ is low pressure gas mixture viscosity defined by Eq. (4), $\mathrm{A}_{0}-4$ 210 are LBC coefficients of $0.1023,0.023364,0.058523,-0.040758$ and 0.0093324 211 respectively.

$$
\begin{gathered}
\zeta=5.35\left(\frac{T_{p c}}{M i^{3} P_{p c}{ }^{4}}\right)^{1 / 6} \\
\rho_{p r}=\frac{\rho}{\rho_{p c}}=\frac{\rho}{M} v_{p c} \\
\mu^{*}=\frac{\sum_{i=1}^{N} z_{i} \mu_{i}}{\sum_{i=1}^{N} z_{i} \sqrt{M_{i}}}
\end{gathered}
$$

212 Kay's mixing rule (Kay, 1936) is utilized to calculate the pseudocritical properties of 213 temperature $T p c$, pressure $P p c$ and volume $v_{p c}$. In Eq. (4) $z_{i}$ is the mole fraction of 214 each pure components $i$ and $M_{i}$ is molecular weight of each component.

215 To establish special relation between $C_{7+}$ fractions and critical volume Eq. (5) 216 suggested by (Lohrenz et al., 1964) is used.

$$
\begin{gathered}
v_{c C_{7+}}=21.573+0.015122 M_{C_{7+}}-27.65 \gamma_{C_{7+}}+ \\
0.070615 M_{C_{7+}} \gamma_{C_{7+}}
\end{gathered}
$$

217 Where $v_{c C_{7+}}$ is the critical molar volume, $M_{C_{7+}}$ is molecular weight and $\gamma_{C_{7+}}$ is specific 218 gravity of $\mathrm{C}_{7+}$ fraction.

219 The component viscosities, $\mu_{i}$ in Eq. (4) is calculated using (Stiel and Thodos, 1962) 220 expression as follows.

221

$$
\left\{\begin{array}{ll}
\mu_{i} \zeta_{i}=\left(34 \times 10^{-5}\right) \operatorname{Tr}^{0.94} & \text { for } \operatorname{Tr} \leq 1.5 \\
\mu_{i} \zeta_{i}=\left(17.78 \times 10^{-5}\right)(4.58 T r-1.67)^{5 / 8} & \text { for } \operatorname{Tr}>1.5
\end{array}\right\}
$$

222

223 In LBC correlation viscosity unit ' $\mu$ ' is in centipoise (cp), viscosity reducing parameter 224 ' $\zeta$ ' is in $\mathrm{cp}^{-1}, \rho$ is in Ibm/ft ${ }^{3}$, specific volume ' $v_{c}$ ' is in $\mathrm{ft} 3 / \mathrm{lbm}$ mol, temperature ' $\mathrm{T}$ ' is in 225 Rankine $\left({ }^{\circ} \mathrm{R}\right)$, pressure ' $\mathrm{P}$ ' is in psia, and molecular weight of each component 'Mi' is 226 in lbm/lbm mol. 
227 The prediction capability of the LBC for viscosity measurement of the hydrocarbon 228 liquid especially in gas condensate reservoirs below the dew point is very poor and rapid increase in liquid viscosity cannot be represented by original LBC correlation (Ali, 230 1991; Hernandez; et al., 2002; Yang et al., 2007). The result of this study illustrated in 231 Fig. (1a) also indicates LBC performance in predicting condensate liquid viscosity is 232 very poor. Hence LBC correlation has been regressed using least-square approach to 233 match the experimental viscosity data. The procedure for tuning of the LBC correlation recommended by Yang et al., (2007) followed in this study. The coefficients of $A_{0-4}$ in LBC correlation Eq. (1) has tuned and new coefficient values are presented in Table. 2.

\begin{tabular}{|c|c|}
\hline Coefficients & New values \\
\hline A0 & 0.11364 \\
\hline A1 & 0.02173 \\
\hline A2 & -0.20666 \\
\hline A3 & 0.06283 \\
\hline A4 & 0.17139 \\
\hline
\end{tabular}

Table 2. The new coefficients for LBC correlations.

238 Fig (1a) depicts the prediction performance of LBC correlation with default and 239 regressed values in predicting condensate viscosity. As it can be seen the 240 performance of the LBC correlation improved significantly after tuning the coefficients. 241 The second types of the empirical correlations, used in this study correlate gas242 saturated-oil viscosity as a function of deal oil viscosity and solution gas to oil ratio. 243 Six well known published literature correlations were selected for this purpose. The prediction performance of gas-saturated-oil correlations found to be poor in forecasting viscosity of condensate liquid and the results associate with large error. Therefore, in 246 this study these correlations have been refined to match the experimental 247 measurements. Table 3 depicts the original and tuned form of the utilized correlations 248 for predicting condensate liquid viscosity.

249 Graphical error analysis of the refined literature correlations in predicting condensate 250 viscosity is presented in Fig (1b-1f). The slope line of $45^{\circ}$ in aforementioned figures representing zero error line in matching between measured and calculated values 252 (Mansour et al., 2013). Qualitative error analysis in terms of coefficient of 253 determination $\left(R^{2}\right)$, absolute average relative deviation percentage (AARD\%), mean 254 square error (MSE) and root-mean square error (RMSE) has been applied. From Fig 255 (1b-1f), and also quantitative error analysis in Table 6, Kartoatmodjo and Schmidt, 256 (1991) outperforms other methods followed by Elsharkawy and Alikhan, (1999), 
257 Bergman, (2000), De Ghetto et al., (1994), Beggs and Robinson, (1975) and LBC, 258 (1964) correlation. The results of tuned correlations compared to the proposed LSSVM 259 and ANN numerical methods, which will be discussed later.

\begin{tabular}{|c|c|c|}
\hline Author & Correlation & Tuned correlation \\
\hline $\begin{array}{l}\text { Beggs \& Robinson, } \\
\text { (1975) }\end{array}$ & $\begin{array}{c}\mu_{o b}=A\left(\mu_{o d}\right)^{B} \\
A=\frac{10.715}{\left(R_{s}+100\right)^{0.515}} \\
B=\frac{5.44}{\left(R_{s}+150\right)^{0.338}}\end{array}$ & $\begin{array}{c}\mu_{c}=A\left(\mu_{o d}\right)^{B} \\
A=\frac{17.99}{\left(R_{s}+100\right)^{0.515}} \\
B=\frac{4.056}{\left(R_{s}+150\right)^{0.338}}\end{array}$ \\
\hline $\begin{array}{l}\text { Kartoatmodjo \& } \\
\text { Schmidt, (1991) }\end{array}$ & $\begin{array}{l}\mu_{o b}=-0.06821+0.9824 X_{1}+4.034 \\
\quad \times 10^{-4} X_{2}^{2} \\
X_{1}=0.43+0.5165 \times 10^{\left(-8.1 \times 10^{-4} R_{S}\right)} \\
X_{2} \\
=[0.2001+0.8428 \\
\left.\times 10^{\left(-8.1 \times 10^{-4} R_{S}\right)}\right] \mu_{o d}{ }^{X 1}\end{array}$ & $\begin{array}{l}\mu_{c}=-0.30612+1.174 X_{1} \\
+4.034 \\
\times 10^{-4} X_{2}{ }^{2} \\
X_{1}=0.43+0.5165 \\
\times 10^{\left(-8.1 \times 10^{-4} R_{S}\right)} \\
X_{2} \\
=[0.2001+0.8428 \\
\left.\times 10^{\left(-8.1 \times 10^{-4} R_{S}\right)}\right] \mu_{o d} X 1\end{array}$ \\
\hline De Ghetto, (1994) & $\begin{array}{l}\text { For }\left({ }^{\circ} \mathrm{API}>31.1\right) \\
\qquad \mu_{o b}=A\left(\mu_{o d}\right)^{B} \\
A=\frac{25.192}{\left(R_{s}+100\right)^{0.6487}} \\
B=\frac{2.7516}{\left(R_{s}+150\right)^{0.2135}}\end{array}$ & $\begin{array}{c}\mu_{c}=A\left(\mu_{o d}\right)^{B} \\
A=\frac{62.96}{\left(R_{s}+100\right)^{0.6487}} \\
B=\frac{2.1334}{\left(R_{s}+150\right)^{0.2135}}\end{array}$ \\
\hline $\begin{array}{c}\text { Elsharkawy \& } \\
\text { Alikhan, (1999) }\end{array}$ & $\begin{array}{c}\mu_{o b}=A\left(\mu_{o d}\right)^{B} \\
A=1241.932\left(R_{s}+641.026\right)^{-1.12410} \\
B=1768.84\left(R_{s}+1180.335\right)^{-1.06622}\end{array}$ & $\begin{array}{l}\quad \mu_{c}=A\left(\mu_{o d}\right)^{B} \\
A \\
=3978.167\left(R_{s}\right. \\
+641.026)^{-1.12410} \\
B \\
=1361.93\left(R_{s}\right. \\
+1180.335)^{-1.06622}\end{array}$ \\
\hline Bergman, (2000) & $\begin{array}{c}\mu_{o b}=A\left(\mu_{o d}\right)^{B} \\
A=e^{\left[4.768-0.8359 \ln \left(R_{S}+300\right)\right]} \\
B=0.555+\frac{133.5}{R_{S}+300}\end{array}$ & $\begin{array}{c}\mu_{c}=A\left(\mu_{o d}\right)^{B} \\
A=e^{\left[4.6792-0.7772 \ln \left(R_{s}+300\right)\right]} \\
B=0.555+\frac{133.5}{R_{s}+300}\end{array}$ \\
\hline
\end{tabular}

Table 3. The original and tuned form of the employed literature correlations for predicting condensate liquid viscosity. 


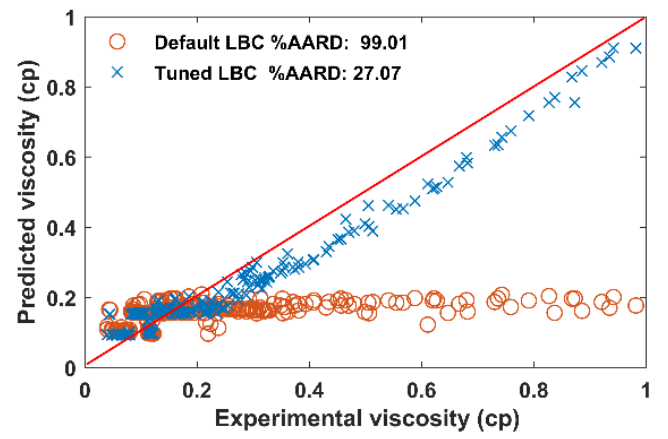

(a)

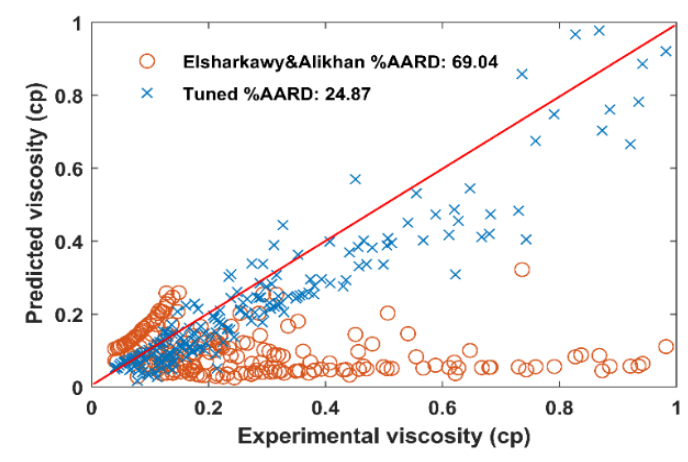

(c)

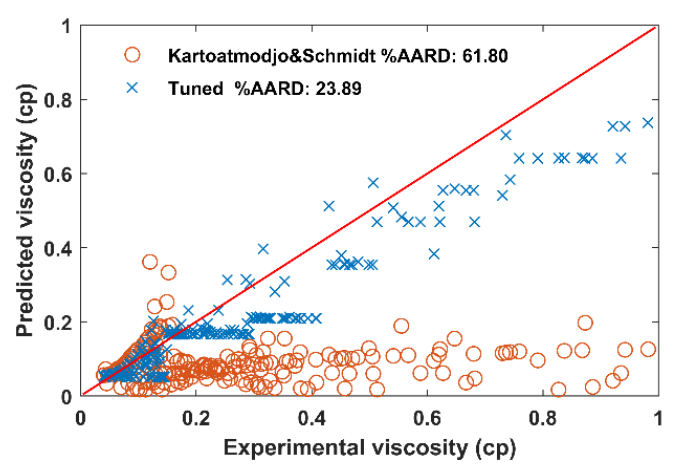

(e)

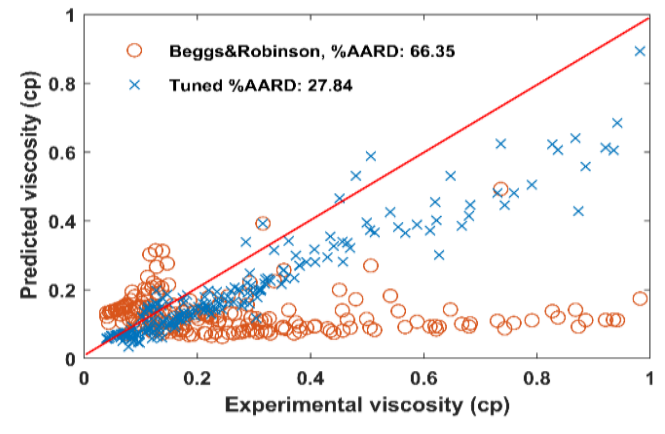

(b)

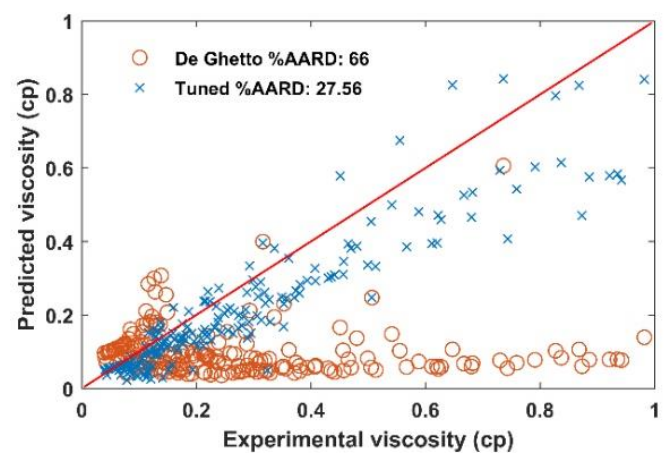

(d)

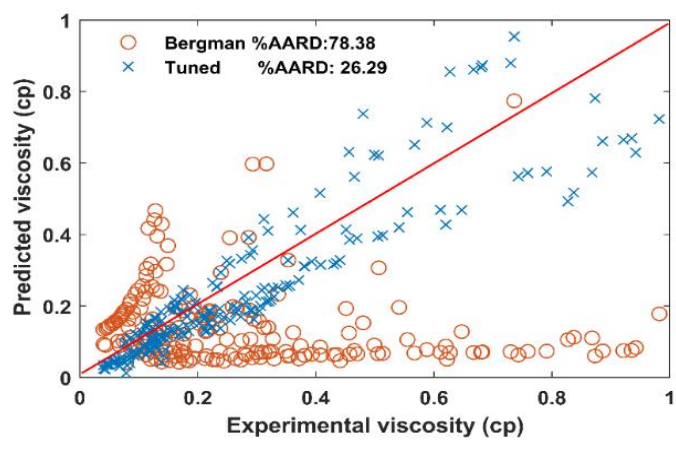

(f)

263 Fig. 1. Cross plot of the experimental viscosity versus predicted viscosity using employed correlations 264 and their tuned results.

\subsection{Least square support vector machine (LSSVM)}

266 The support vector machine (SVM) has been identified as an efficient and powerful

267 strategy developed from the machine-learning community (Cortes and Vapnik, 1995;

268 Curilem et al., n.d.; Suykens et al., 2002). SVM is a tool for a set of related supervised 269 learning methods that analyse data and recognize pattern using regression analysis 270 and it is identified as a non-probabilistic binary linear classifier. The objective of this 271 study is to develop a nonlinear relationship between the available experimental data 272 considered as inputs (pressure, temperature, API gravity, gas to oil ratio and gas 273 specific gravity) and the desired output (liquid dropout or condensate liquid viscosity) 
274 (Ahmadi and Ebadi, 2014; Eslamimanesh et al., 2012; Hemmati-Sarapardeh et al., 275 2014; Kamari et al., 2013).

276 SVM method has many advantages over other machine learning techniques as 277 follows: they are more likely to converge to the global optima, prior determination of 278 the network is not required in this model and can be automatically determined as the 279 training ends. Furthermore, the number of hidden layers and hidden nodes should not 280 be determined and this algorithm has fewer adjustable parameters compared to ANN 281 network (Eslamimanesh et al., 2012; Suykens et al., 2002).

282 Original SVM algorithm requires implementing set of nonlinear equations using 283 quadratic programming, which is very hard to implement. Also the obtained outputs 284 using SVM algorithm is much scattered for both linear and nonlinear regressions 285 (Eslamimanesh et al., 2012; Suykens et al., 2002; Suykens and Vandewalle, 1999). 286 To overcome abovementioned problems Suykens and Vandewalle, (1999) suggested 287 a modification to the original SVM algorithm named Least-Squares Support Vector 288 Machine (LSSVM). The LSSVM only requires solving set of linear equations, makes it 289 easier to implement and faster alternative to the original SVM method (Eslamimanesh 290 et al., 2011; Pelckmans et al., 2002; Suykens and Vandewalle, 1999). Suykens and 291 Vandewalle, (1999) defined the cost function (J) for LSSVM by Eq. (7).

$$
J=\frac{1}{2} w^{T} w+\frac{1}{2} \gamma \sum_{k=1}^{N} e_{k}^{2}
$$

292 Eq. (7) is subjected to the following constraint:

$$
y_{k}=\left[w^{T} \varphi\left(x_{k}\right)+b+e_{k}\right], \quad k=1, \ldots, N .
$$

293 Where, $x_{k}$ is input vector containing the input parameters (pressure, temperature, 294 solution gas to oil ratio and gas specific gravity), $y_{k}$ is output vector (condensate liquid 295 viscosity), b stands for intercept of linear regression in LSSVM method, $w$ stands for 296 regression weight, $e_{k}$ is the regression error for $\mathrm{N}$ training objects in least-squares 297 error approach, $\gamma$ is relative weight of the summation of the regression errors 298 compared to the regression weight (right hand side of Eq. (7), $\varphi$ is the feature map, 299 mapping the feasible input region to the high dimensional feature space and transcript 300 T stands for transposing the matrix.

301 Applying Lagrangian function, the regression weight $w$ can be defined in Eq. (9). 


$$
w=\sum_{k=1}^{N} \alpha_{k} x_{k}
$$

302 Where

$$
\alpha_{k}=2 \gamma e_{k}
$$

$303 a_{k}$ denotes to the Lagrange multiplier, that may be either positive or negative, since 304 LSSVM has equality restrictions. Assuming linear regression between the inputs and 305 output parameters of LSSVM algorithm, Eq. (8) is re-written as follows (Pelckmans et 306 al., 2002; Suykens et al., 2002; Suykens and Vandewalle, 1999).

$$
\alpha_{k}=\frac{\left(y_{k}-b\right)}{x_{k}^{T} x+(2 \gamma)^{-1}}
$$

307 The linear regression in Eq. (11) can be converted to a nonlinear using the Kernel 308 function in Eq. (12)

$$
f(x)=\sum_{k, l=1}^{N} \alpha_{k} K\left(x, x_{k}\right)+b
$$

309 Where $K\left(x, x_{k}\right)$ represents dependency of Kernel function to the inner values of two 310 vectors $x$ and $x_{k}$ in the feasible region built by the inner product of the vectors $\phi(x)^{T}$ 311 and $\phi\left(x_{i}\right)$ as follows: (Cortes and Vapnik, 1995; Eslamimanesh et al., 2012; Fazeli et 312 al., 2013; Suykens et al., 2002; Suykens and Vandewalle, 1999).

$$
K(x, x k)=\phi(x)^{T} \phi\left(x_{k}\right)
$$

313 The radial basis function (RBF) Kernel defined in Eq. (14) has been executed. (Cortes 314 and Vapnik, 1995; Eslamimanesh et al., 2012; Pelckmans et al., 2002; Suykens et al., 315 2002):

$$
K\left(x, x_{k}\right)=\exp \left(-\frac{\left\|x_{k}-x\right\|^{2}}{\sigma^{2}}\right)
$$

316 Where $\sigma$ in Eq. (14) and $\gamma$ in Eq. (7) are tuning parameters of LSSVM and can be 317 determined by any external optimization algorithm. Robust Simulated Annealing (SA) 318 algorithm in MATLAB optimization toolbox has been used to find the optimum values 319 of these parameters. The root mean square error (RMSE) between the developed 320 LSSVM model obtained results and experimental values, defined by Eq. (15), was 321 considered as an objective function during the SA computation.

$$
R M S E=\sqrt{\frac{\sum_{i=1}^{n}\left(V i s_{\text {esti }}-V i s_{\text {expi }}\right)^{2}}{n s}}
$$


322 Where Vis represents condensate viscosity, subscripts est and exp represent the 323 predicted and actual value, $n s$ is number of data points from the initial assigned 324 population of 144 data sets. The optimized values of $\gamma$ and $\sigma^{2}$ using SA optimization 325 method for predicting the condensate liquid viscosity presented in Table 4.

\begin{tabular}{|c|c|c|c|}
\hline \multirow[t]{2}{*}{ LSSVM model } & \multirow[t]{2}{*}{ Input parameters } & \multicolumn{2}{|c|}{ Model parameters } \\
\hline & & $\gamma$ & $\sigma^{2}$ \\
\hline $\begin{array}{l}\text { Condensate phase } \\
\text { viscosity }\end{array}$ & $\begin{array}{l}\text { Reservoir pressure, } \\
\text { Temperature, API, gas SG, Rs }\end{array}$ & 5625.256 & 23.65 \\
\hline
\end{tabular}

Table 4. The optimum values of the LSSVM parameters.

327 In this study the data is divided into three subsets of "Training", "Optimization" and 328 "Testing". Training set is used for generating the model structure, optimization is used 329 for minimization of the error in trained model and test data is used to investigate the 330 prediction capability of the developed model.

331 The database was randomly split into three sub data sets of $80 \%$ training, $10 \%$ testing 332 and $10 \%$ validation. The allocation percentage of the data is selected according to the recommendations by Ahmadi and Ebadi, (2014) and Eslamimanesh et al., (2012).

334 During the training of the model cross validation has been performed where, the 335 training data sets into several folds and accuracy of each fold checked. Table 5 is presenting the statistical error analysis of the LSSVM in each stage of training, optimizing and testing.

338 Input variables for this model are as pressure, temperature, API gravity, gas specific 339 gravity and solution gas to oil ratio "Rs". The acceptable distribution of the data is one with homogeneous accumulations of the data on the domain of the three data sets

341 (Eslamimanesh et al., 2011; Gharagheizi et al., 2014).

342 The MATLAB code for trained LSSVM model generated and prediction capability of 343 the trained model was tested for new data sets. The graphs in Fig. 2 and Fig. 3 are 344 indicating the performance of LSSVM model in training stage and in predicting new experimental set of data (testing stage), respectively. The majority (73\%) of the data points in this study are within lower viscosity range of $0-0.4 \mathrm{cp}$. Therefore, the testing 347 of the data is toward lower viscosity region, which is more realistic characterisation of 348 gas condensate viscosity below the dew point near wellbore region (Whitson et al., 349 1999; Yang et al., 2007). The viscosity of condensate liquid in near wellbore region, 350 where condensate liquid in mobile is very low. This is due to existence of more lighter 
$351 \mathrm{C}_{7+}$ fractions in mobile condensate liquid composition in aforementioned region 352 (Fevang, 1995, p. 44). Even though the higher viscosity prediction in Fig. (3) has 353 higher error than the lower viscosity prediction, the AARD\% is still reasonably small 354 because the majority $(73 \%)$ of the values are in lower viscosity region.

355 Fig. 4 is representing residual plot of LSSVM trained data. Ability of the trained LSSVM 356 in predicting new data sets are also analysed by presenting graph of standard 357 deviation error in Fig. 5 and standard error from the mean in Fig. 6.

358

\begin{tabular}{|c|c|c|c|c|}
\hline Stage of the process & $R^{2 \mathrm{a}}$ & RMSE $^{\mathrm{b}}$ & MSE $^{\mathrm{c}}$ & AARD\% $^{\mathrm{d}}$ \\
\hline Training set & 0.9139 & 0.10845 & 0.01176 & 13.96 \\
\hline Optimization set & 0.87256 & 0.111121 & 0.012348 & 14.12 \\
\hline Testing set & 0.7723 & 0.121037 & 0.01465 & 14.25 \\
& & & & \\
\hline
\end{tabular}

Table 5. Statistical error performance of the LSSVM.

360

a $\quad R^{2}=1-\frac{\sum_{i}^{N}(\text { cal. }((i)) / \text { Est. }(i)-\exp .(i))^{2}}{\sum_{i}^{N}(\text { cal. }((i)) / \text { Est. }(i)-\text { average }(\exp .(i)))^{2}}$

361

b $\quad R M S E=\left(\frac{\sum_{i}^{N}(\text { cal. } .((i)) / E s t .(i)-\exp .(i))^{2}}{N}\right)^{0.5}$

362

C $\quad M S E=\left(\frac{\left.\sum_{i}^{N}(\text { cal. } .(i)) / E s t .(i)-\exp .(i)\right)^{2}}{N}\right)$

363

$\mathrm{d} \quad A A R D \%=\frac{100}{N} \sum_{i}^{N} \frac{\mid(\text { cal. }((i)) / \text { Est.(i) }-\exp .(i) \mid}{\exp .(i)}$

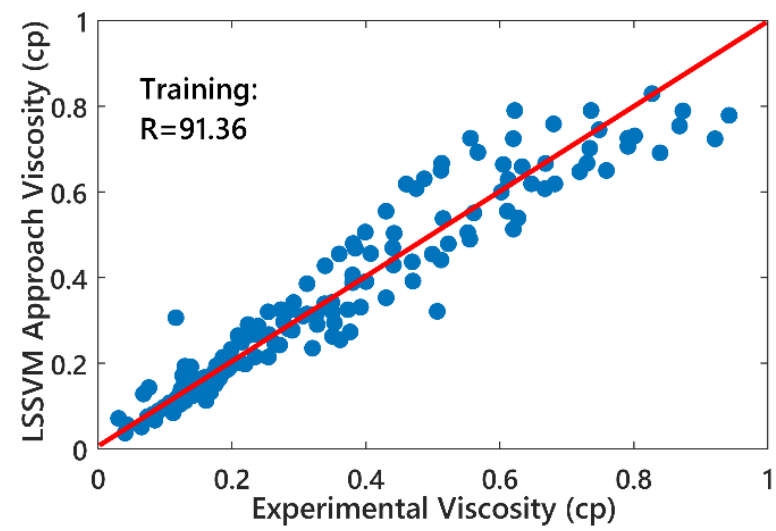

Fig. 2. Performance of the LSSVM trained model $\left(R^{2}=0.9136\right)$. 


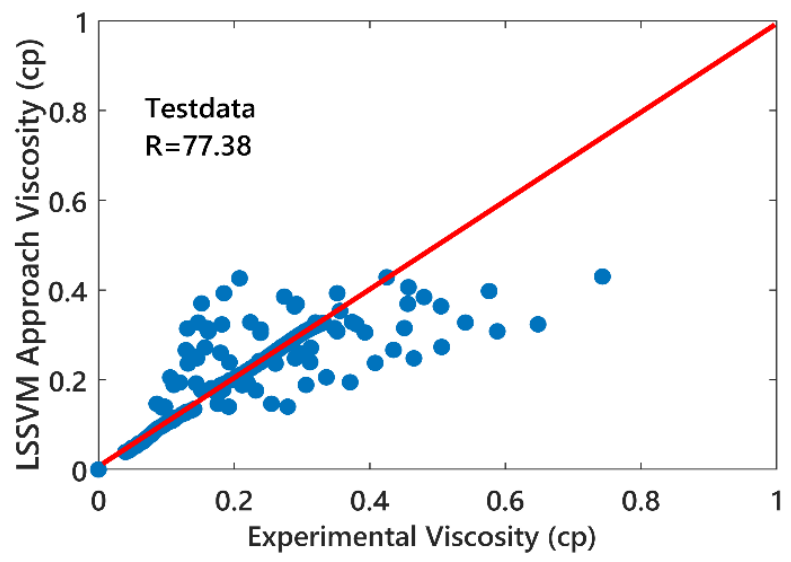

Fig. 3. Performance of LSSVM in predicting new data $\left(R^{2}=0.7738\right)$.

369

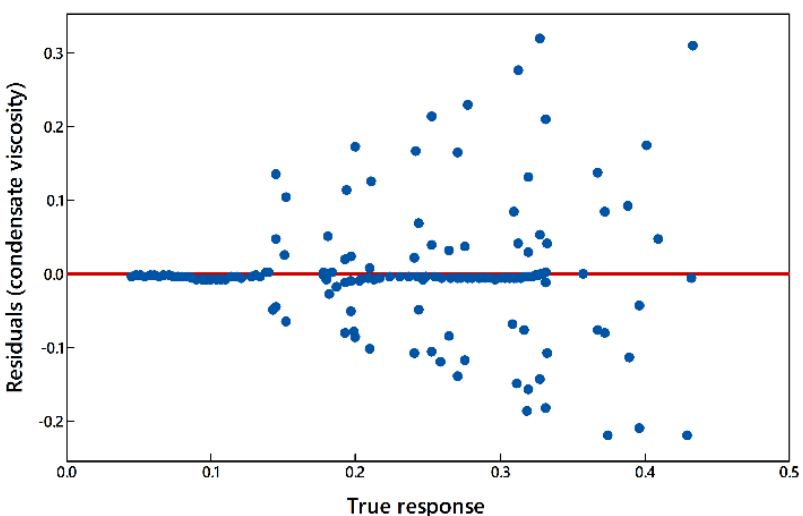

Fig. 4. Residual plot of LSSVM trained data.

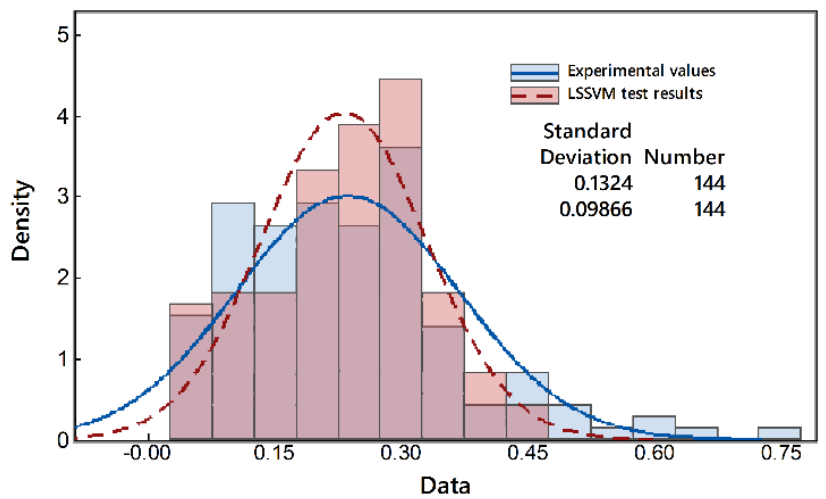

Fig. 5. Graph of standard deviation of LSSVM method against experimental data. 


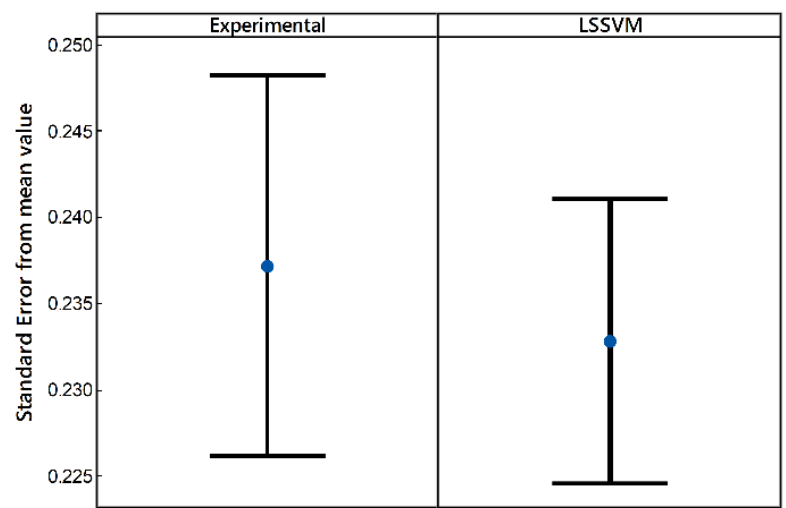

Fig. 6. Interval plot of experimental data against LSSVM approach.

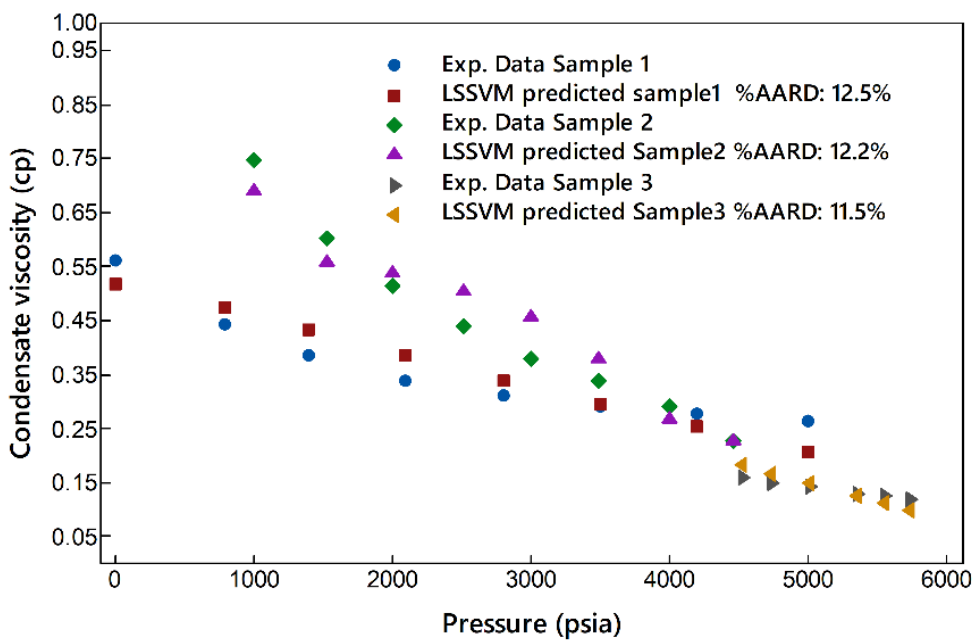

Fig. 7. Comparison between experimental and predicted values provided by LSSVM for three samples 378 of condensate fluid viscosity.

380 The primary aim of this study was to develop a model that predicts viscosity of the 381 condensate liquid in depleted gas condensate reservoirs with high accuracy using machine learning techniques. The results indicate that LSSVM is performing better 383 than tuned literature correlations. However, the error is still high, approximately about $38423 \%$ in testing stage, where the capability of the model assessed using new data sets. 385 Therefore, to certify the effectiveness and accuracy of the suggested LSSVM model 386 for estimation of condensate viscosity among smart approaches in another attempt an 387 Artificial Neural Network (ANN) was developed, which is presented in following 388 section.

\subsection{Artificial Neural Networks (ANN)}

390 A detailed description of neural networks can be found in Cios and Shields (1997), 391 Dreyfus (2005) and Haykin (1994). ANN is a computational technique in artificial 392 intelligence that uses complex computation system for predicting the output responses. ANNs are inspired by biological networks, performing in a massive parallel 
connection between nonlinear, parametrized, and bounded functions called neurons

395 (Cios and Shields, 1997; Mesbah et al., 2017).

396 Such a network is a massively parallel-distributed processor that has a natural 397 tendency for storing experimental knowledge and making it available for future use. In 398 ANN system knowledge is acquired by the network through a learning process and 399 synaptic weights will store this knowledge (Haykin, 1994). Hence, mathematical 400 interpretation of the problem does not required. Neurons in such a system coordinate 401 their work, and they transfer information by using synapses "electromagnetic 402 communications" (Ghaffari et al., 2006). Through a set of known input (5 in this study) 403 and output data ( 1 in this study), the network will be trained. Through a learning 404 405 process the network monitors the error between the predicted and desired outputs and continue to adjust the weights until the optimization criteria are reached. This process 406 is usually carried out in two stages: first the input variables are linearly combined, then 408 the result is used as argument of non-linear activation function (a). The activation 409 function must be non-decreasing and differentiable function; the most common choices are either the identity function $(y=x)$, or bounded sigmoid (s-shaped) 410 function, as the logistic $\left[y=1 /\left(1+e^{-x}\right)\right]$ (Eslamimanesh et al., 2011; Ghaffari et al., 411 2006; Haykin, 1994; Hippert et al., 2001).

412 The neurons are organized in a way that define the network architecture. We used 413 multilayer perception (MLP) type, in which the neurons are organized in layers Fig. 414 (8). The neurons in each layer may share same inputs, but they are not connected to 415 each other. The neural networks consist of hidden layers, output layer, inputs and bias units. Number of hidden layers and number of neuron of each layers can be arbitrary 417 (Khosrojerdi et al., 2016). However, increasing number of neurons may cause 418 overfitting while decreasing their numbers may result on poor performance of the 419 network. The main advantage of ANN is ability to process large amount of data sets 420 (Ghaffari et al., 2006; Khosrojerdi et al., 2016; Mesbah et al., 2017; Hippert et al., 421 2001).

422 Fig. (8) depicts the schematic diagram of ANN structure for predicting viscosity of 423 condensate liquid fluid. This design has one layer for inputs consists of five input 424 parameters, one hidden layer, two bias units and one output unit. This architecture 425 recommended by Hagan et al. (2014), Hagan and Menhaj (1994) and Hippert et al. 426 (2001) as an efficient and the most popular multilayer feed-forward architecture. 427 Nevertheless, there is large number of other designs, which might be considered 
suitable for other applications. Further information about ANN network architecture used in this study is presented in Appendix B.

430 The network is designed in MATLAB and calculations carried out by implementing 431 different number of neurons in hidden layer (layer 2). To select the best architecture 432 in terms of number of neurons in a hidden layer a trial and error procedure was 433 implemented. The performance of each structure was assessed by comparing 434 coefficient of determination $\left(R^{2}\right)$ and root man square error (RMSE). We came up with 435 the proposed structure in Fig. (8) (5 neurons in layer 2) as the best topology.

436 The aforementioned architecture performance evaluation is required to determine the 437 complexity of a neural network as one of the important factors. Hagan et al, (2014) 438 and Soroush et al, (2015) highlighted importance of level of complexity in neural 439 network structure to ovoid overfitting with higher number of neurons and poor 440 performance with not enough number of neurons.

441 Our input parameters are API gravity, solution gas to oil ratio (Rs), pressure, 442 temperature and gas specific gravity. The output layer is viscosity of condensate fluid 443 calculated by the ANN network. There are many algorithms available to train the 444 network and minimize the error and find the optimum values of the weights and biases; 445 including Levenberg-Marquardt (LM), scaled conjugate gradient (SCG), and resilient 446 back propagation (Hippert et al., 2001; Soroush et al., 2015).

447 The LM backpropagation algorithm introduced by Kenneth, (1944) and recommended 448 by Behera and Chattopadhyay, (2012) as one of the fastest and most popular 449 backpropagation algorithm was used for adjusting the weights in this study. The 450 tangent sigmoid transfer functions set for the neurons in hidden layer.

451 For training of the model $70 \%$ of whole data bank (210 data points) randomly selected 452 and split to three data sets of $80 \%$ (168 data points) for training, $10 \%$ (21 data points) 453 for validation and $10 \%$ (21 data points) for testing.

454 The ANN network is trained to map input data by iterative adjustment of the weight 455 function. Information from inputs feed forwarded through the network to optimize the 456 weight between the neurons. Optimization of the weight function is carried out by back 457 propagation of the error during training or learning stages. The ANN reads the inputs 458 and output values in training stage and changes the value of weight functions to 459 minimise the difference in predicted and the target (observed) values. The error in 460 prediction is minimized across training iterations (epochs) and training continues to 461 the point that the network reaches a specified level of accuracy (Ghaffari et al., 2006). 
462 Once the model has reached satisfactory accuracy or the model is converged, the 463 training will stop. The performance of the ANN trained model for the training stage is 464 presented in Fig. (9) and Fig. (10).

465 Fig. (7) and Fig. (11) depict the performance of the developed LSSVM and ANN 466 models respectively in predicting the condensate viscosity data. As it can be seen from 467 the aforementioned figures both LSSVM and ANN network predict the independent 468 sample data with satisfactory accuracy. This will be discussed in details in results 469 section.

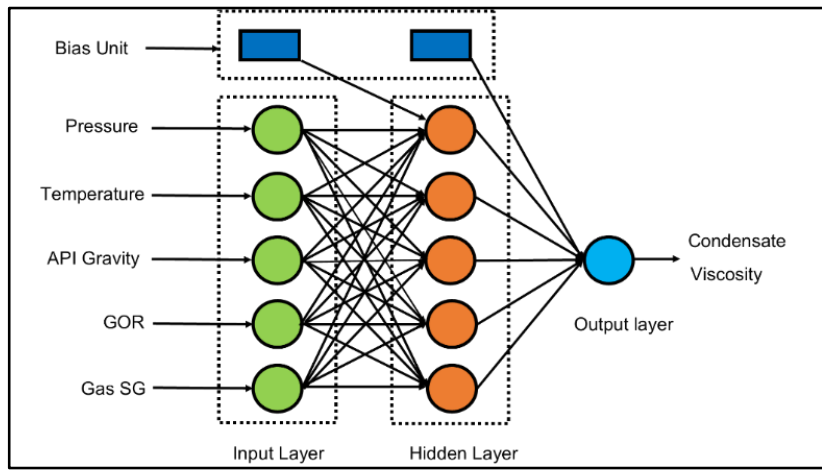

Fig. 8. Developed ANN model architecture for prediction of condensate liquid viscosity.

474 Fig. 9. Prediction performance of developed ANN network for condensate liquid viscosity in training 475 stage.

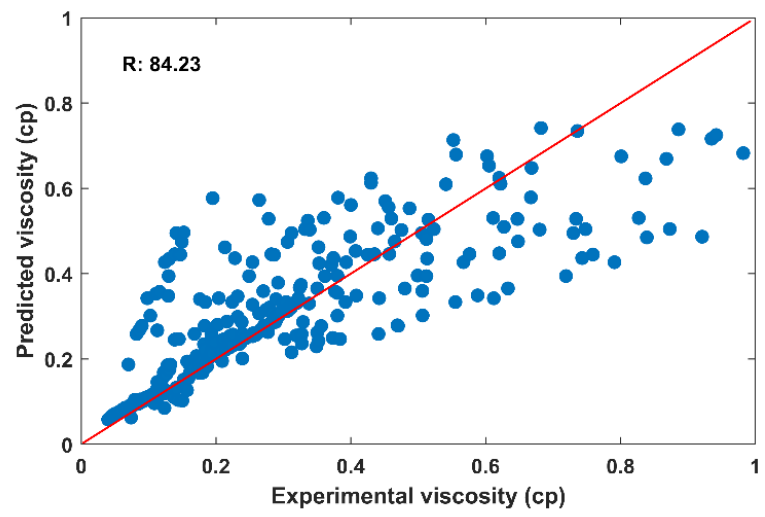




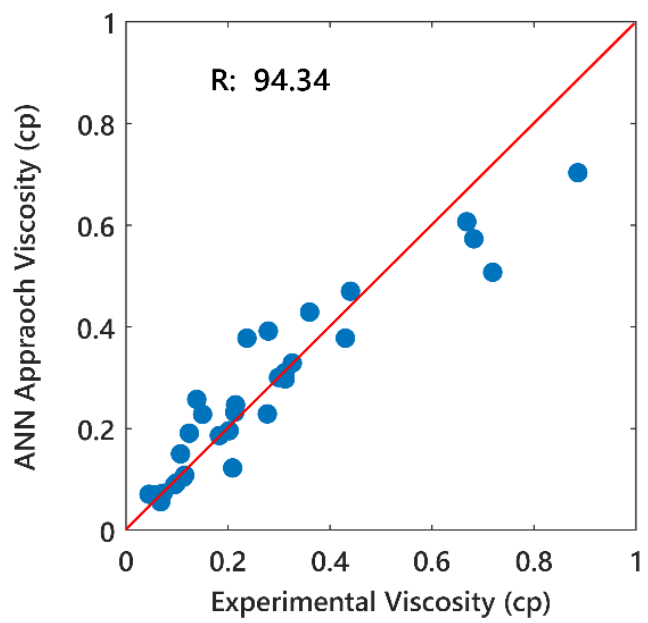

Fig. 10. Prediction performance of ANN network for condensate liquid viscosity in testing stage.

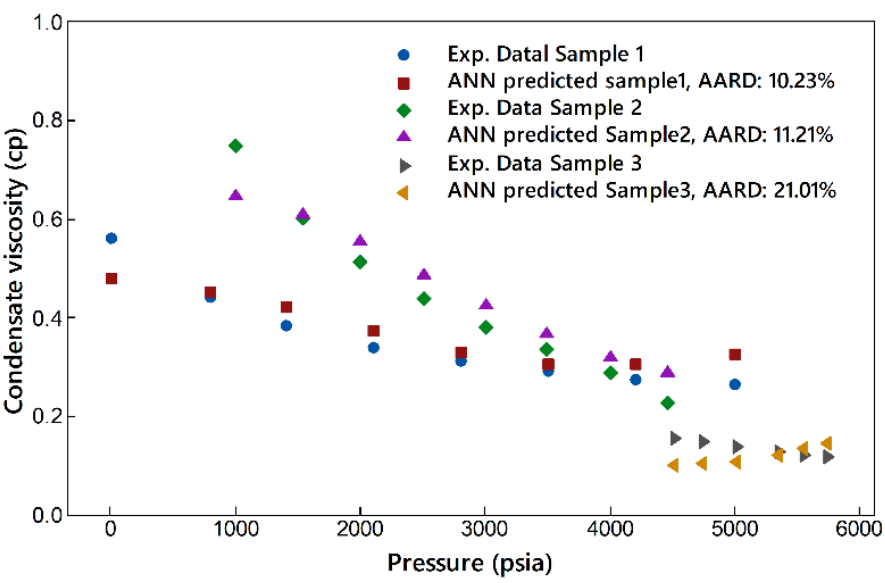

Fig. 11. Prediction performance of ANN model for 3 condensate liquid viscosity samples as a function of pressure.

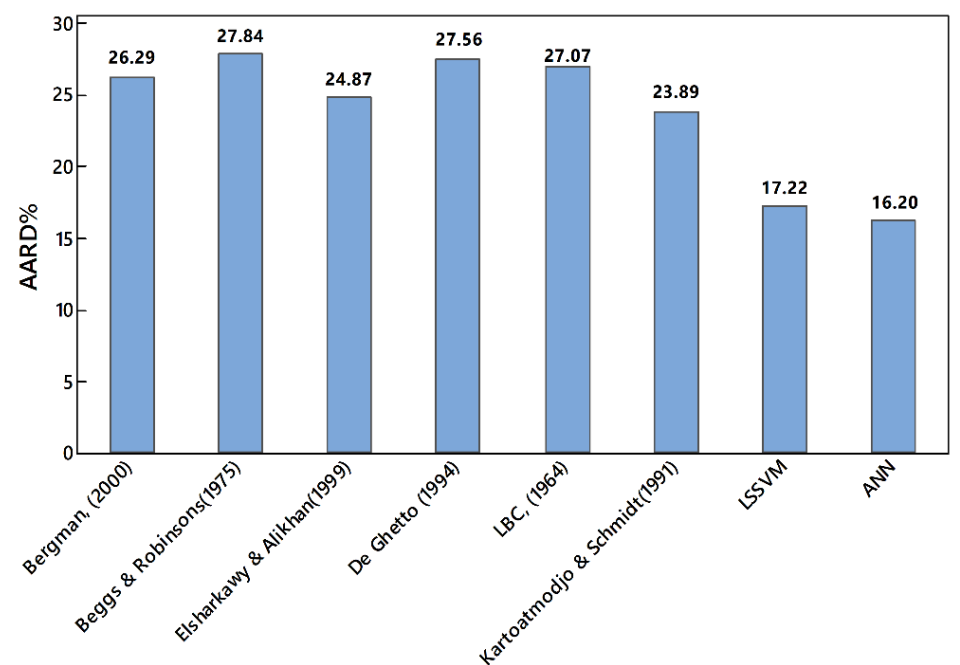

Fig. 12. Performance comparison of employed methods in this study in predicting experimental condensate liquid viscosity. 
488

489

490

491

492

493

494

495

496

497

498

499

500

501

502

503

504

505

506

507

508

509

510

511

\begin{tabular}{|c|c|c|c|c|}
\hline Method & $\mathrm{R}^{2}$ & RMSE & MSE & AARD $\%$ \\
\hline LBC (1964) & 0.7241 & 0.1240 & 0.0154 & 27.07 \\
\hline Bergman (2000) & 0.7297 & 0.1236 & 0.0153 & 26.29 \\
\hline $\begin{array}{c}\text { Beggs and Robinson } \\
\text { (1975) }\end{array}$ & 0.7207 & 0.1244 & 0.0155 & 27.84 \\
\hline $\begin{array}{l}\text { Elsharkawy and Alikhan } \\
\text { (1999) }\end{array}$ & 0.7344 & 0.1228 & 0.0151 & 24.87 \\
\hline De Ghetto (1994) & 0.7243 & 0.1240 & 0.0154 & 27.56 \\
\hline $\begin{array}{l}\text { Kartoatmodjo and } \\
\text { Schmidt (1994) }\end{array}$ & 0.7412 & 0.1220 & 0.0149 & 23.89 \\
\hline LSSVM & 0.7738 & 0.1208 & 0.0146 & 17.22 \\
\hline ANN & 0.8423 & 0.1144 & 0.0131 & 16.20 \\
\hline
\end{tabular}

Table 6. Statistical parameters of developed models and utilized correlation for prediction of condensate liquid viscosity.

\section{Results and discussion}

In this study two intelligent based models of LSSVM and ANN were developed to predict condensate liquid viscosity in depleted gas condensate reservoirs near wellbore region.

In first phase of this study prediction performance of LBC compositional model and 5 gas-saturated-oil empirical literature correlations were investigated for prediction of condensate viscosity.

The prediction performance of the compositional method of LBC, (1964) in predicting condensate liquid viscosity is very poor (Yang et al., 2007) and adjustment of LBC coefficients are usually necessary to match the experimental condensate viscosity (Fevang and Whitson, 1996; Whitson et al., 1999; Yang et al., 2007). The statistical analysis of the results shown in Fig. (1a) confirm the poor performance of compositional based LBC model. The reason for this is might due to the sensitivity of LBC method to mixture density and critical volumes of the heavy components. Hence, in this study the coefficients of the LBC correlation have tuned using least-square approach to match the experimental condensate viscosity data. Fig. (1a) representing the prediction performance of LBC, (1964) with default and adjusted coefficients.

The coefficients of five well-known gas-saturated-oil viscosity literature correlations regressed to match the condensate experimental data. The results of these regressions presented in Fig. $(1 \mathrm{~b}-\mathrm{f})$. These empirical correlations are function of dead oil viscosity and solution gas to oil ratio. It should be noted that dead oil viscosity 
512 is one of the most "difficult" properties to be estimated by correlations due to its 513 dependency to paraffin, aromatic, naphthalene and asphaltene content (Hemmati514 Sarapardeh et al., 2014; Whitson et al., 2000). This might be one of the reasons for 515 poor performance of the default empirical gas-saturated-oil viscosity correlations. 516 Moreover, these correlations were originally developed using crude oil samples, which 517 its properties are fundamentally different from condensate liquid.

518 Poor performance of the published literature correlations in predicting liquid dropout 519 viscosity, motivated to develop two machine leaning models of LSSVM and ANN 520 network in this study. The performance of the newly proposed models LSSVM and 521 ANN were compared against refined previously published correlations through 522 graphical and statistical error analysis. The statistical error analysis results carried out 523 in terms of coefficient of determination $\left(R^{2}\right)$, Root Mean Square Error (RMSE), 524 Average Absolute Relative Deviation (AARD\%) and Mean Square Error (MSE). The 525 result of this error analysis is tabulated in the Table 6. Graphical representation of 526 AARD\% is also provided in Fig. (12). The results in Table 6 and Fig. (12) indicate ANN 527 model outperforms other methods with AARD of $16.20 \%, \mathrm{R}^{2}$ of 0.8423 , RMSE of 5280.1144 and MSE of 0.0131. ANN followed by LSSVM, Kartoatmodjo and Schmidt 529 (1994), Elsharkawy and Alikhan (1999), Bergman (2000), LBC (1964), De Ghetto et 530 al. (1994) and Beggs and Robinson (1975).

531 The results show using either compositional model of LBC or gas-saturated-oil 532 viscosity literature correlations require significant tuning of coefficients for viscosity 533 prediction of condensate liquid. Whereas developed two intelligent approaches were 534 able to monitor condensate liquid viscosity with appropriate precision and integrity.

535 Non-linear relationship between the available experimental data and the desired 536 outputs created using developed LSSVM model. The optimum values of two important 537 tuning parameters of LSSVM include $\sigma^{2}$ and $\gamma$ are presented in Table 2. Simulated 538 Annealing optimization (SA) algorithm was applied to achieve these two optimum 539 values.

540 The ability of proposed LSSVM and ANN models for calculating condensate liquid 541 viscosity as a function of changing pressure has been investigated for three gas 542 condensate samples from literature. Fig. (7) and Fig. (11) are demonstrating 543 experimental and predicted condensate liquid viscosities using LSSVM and ANN 544 models respectively. The results show that both models are able to forecast physical 545 trend of experimental condensate viscosity. The accuracy of the models for predicting 
546 condensate viscosity of independent samples determined by AARD\%. The error

547 analysis show that both models perform well with acceptable level of accuracy.

548 From Fig. (7) and Fig. (11) it is evident that increasing pressure decreases the 549 condensate viscosity. The pressure changes due to depletion in gas condensate 550 reservoirs can have significant effect on condensate viscosity variation near wellbore 551 region (Fevang and Whitson, 1996). This changes can be due to the complex 552 behaviour of gas condensate reservoir below the dew points, which violate 553 thermodynamic laws. The developed LSSVM and ANN models successfully captured 554 the trend of condensate viscosity while utilized correlations were not accurate enough 555 in tracking these changes.

556 Although the prediction performance of the LSSVM was better than published 557 literature correlations, however the error was still high with $\mathrm{R}^{2}$ of 0.7738 and AARD of 558 17.22\%. Therefore, Artificial Neural Network (ANN) method was used aiming for more 559 accurate ML modelling approach. Performance prediction of ANN network is a function 560 of number of neurons that is used in hidden layer (layer 2 in Fig. 8). A trial and error 561 approach were implemented to find the optimum number of neurons. For this study 562 the ANN architecture with five neurons provide the most satisfying results with least 563 RMSE and the highest $\mathrm{R}^{2}$.

\section{Conclusion}

565 Better modelling of condensate viscosity is very important for optimizing future 566 recoveries, simulation studies, PVT calculations and accurate production performance 567 forecast of gas condensate reservoirs. Current techniques in literature are providing 568 poor prediction performance of condensate viscosity in near wellbore region. Hence 569 in this study efforts have been made to model this liquid dropout viscosity using 570 numerical artificial intelligence based methods including Least Square Support Vector 571 Machine (LSSVM) and Artificial Neural Network (ANN). Both LSSVM and ANN models 572 are capable of simulating the actual physical trend of the condensate viscosity in gas 573 condensate reservoirs with variation of condensate API gravity, reservoir pressure, 574 reservoir temperature, solution gas to oil ratio (Rs) and gas specific gravity. The 575 advantage of LSSVM is that overfitting is not possible with this method. The robust 576 simulated annealing optimizer implemented to find two important tuning parameters $577 \quad \sigma^{2}$ and $\gamma$ and tune LSSVM method. 
The results of this study indicated that proposed ANN and LSSVM are more robust, efficient and reliable than literature correlations. In ANN approach care should be taken to not over fit the data. This can be done by designing a network with appropriate level of complexity such as number of neurons and hidden layers.

582 Tuning the evolved LSSVM and ANN approach with other optimization method such as Genetic Algorithm (GA) or Coupled Simulated Annealing (CSA) to reduce the error can be considered for future studies.

Simplicity and flexibility of the developed model make them a good candidate to determine the viscosity of the condensate liquid in depleted gas condensate reservoirs. The developed models can be implemented in PVT calculation of gas condensate reservoirs for more accurate and reliable modelling of such reservoirs.

Ahmadi, M.A., Ebadi, M., 2014a. Fuzzy Modeling and Experimental Investigation of Minimum Miscible Pressure in Gas Injection Process. Fluid Phase Equilib. 378, 1-12. https://doi.org/10.1016/j.fluid.2014.06.022

Ahmadi, M.A., Ebadi, M., 2014b. Evolving smart approach for determination dew point pressure through condensate gas reservoirs. Fuel 117, 1074-1084. https://doi.org/10.1016/J.FUEL.2013.10.010

Ahmadi, M.A., Ebadi, M., Hosseini, S.M., 2014. Prediction breakthrough time of water coning in the fractured reservoirs by implementing low parameter support vector machine approach. Fuel 117, 579-589. https://doi.org/10.1016/j.fuel.2013.09.071

Ahmed, T.H., 2010. Reservoir engineering handbook, 4th ed. Gulf Professional Pub, Oxford.

Al-Meshari, A., Kokal, S., Al-Muhainy, A., Ali, M., 2007. Measurement of Gas Condensate, Near-Critical and Volatile Oil Densities and Viscosities at Reservoir Conditions, in: Proceedings of SPE Annual Technical Conference and Exhibition. Society of Petroleum Engineers, California. https://doi.org/10.2523/108434-ms

Al-Nasser, K.S., Al-Marhoun, M.A., 2012. Development of New Gas Viscosity Correlations, in: SPE International Production and Operations Conference \& Exhibition. Society of Petroleum Engineers, Doha. https://doi.org/10.2118/153239-ms

Ali, J.K., 1991. Evaluation of correlations for estimating the viscosities of hydrocarbon fluids. J. Pet. Sci. Eng. 5, 351-369. https://doi.org/10.1016/09204105(91)90053-P

Audonnet, F., Pádua, A.A.., 2004. Viscosity and density of mixtures of methane and n-decane from 298 to $393 \mathrm{~K}$ and up to $75 \mathrm{MPa}$. Fluid Phase Equilib. 216, 235244. https://doi.org/10.1016/J.FLUID.2003.10.017

Beggs, H.D., Robinson, J.R., 1975. Estimating the Viscosity of Crude Oil Systems. J. Pet. Technol. 27, 1140-1141. https://doi.org/10.2118/5434-PA

Behera, S.S., Chattopadhyay, S., 2012. A Comparative Study of Back Propagation and Simulated Annealing Algorithms for Neural Net Classifier Optimization. Procedia Eng. 38, 448-455. https://doi.org/10.1016/J.PROENG.2012.06.055 
Bergman, D.F., Sutton, R.P., 2007. An Update to Viscosity Correlations for GasSaturated Crude Oils, in: SPE Annual Technical Conference and Exhibition. Society of Petroleum Engineers, Anaheim. https://doi.org/10.2118/110195-MS Chen, H.L., Wilson, S.D., Monger-McClure, T.G., 1995. Determination of Relative Permeability and Recovery for North Sea Gas Condensate Reservoirs, in: SPE Annual Technical Conference and Exhibition. Society of Petroleum Engineers, Dallas. https://doi.org/10.2118/30769-MS

Cios, K.J., Shields, M.E., 1997. The handbook of brain theory and neural networks: By Micheal A. Arbib (Ed.), MIT Press, Cambridge, MA, 1995, ISBN 0-26201148-4, 1118 pp. Neurocomputing 16, 259-261. https://doi.org/10.1016/S09252312(97)00036-2

Cortes, C., Vapnik, V., 1995. Support-vector networks. Mach. Learn. 20, 273-297. https://doi.org/10.1007/BF00994018

Curilem, M., Acuña, G., ... F.C.-C.E., 2011, undefined, n.d. Neural networks and support vector machine models applied to energy consumption optimization in semiautogeneous grinding. folk.ntnu.no.

De Ghetto, G., Paone, F., Villa, M., Spa, A., 1994. Reliability Analysis on PVT Correlations, in: European Petroleum Conference. SPE, London.

Dreyfus, G., 2005. Neural Networks: Methodology and Applications, 1st ed. Springer-Verlag Berlin Heidelberg, Paris.

ECLIPSE, 2014. Eclipse Reservoir Simulation Reference Manual.

El Aily, M., Mansour, E.M., Desouky, S.M., Helmi, M.E., 2019. Modeling viscosity of moderate and light dead oils in the presence of complex aromatic structure. J. Pet. Sci. Eng. 173, 426-433. https://doi.org/10.1016/J.PETROL.2018.10.024

Elsharkawy, A.M., Alikhan, A.A., 1999. Models for predicting the viscosity of Middle East crude oils. Fuel 78, 891-903. https://doi.org/10.1016/S00162361(99)00019-8

Elsharkawy, A.M., Foda, S.G., 1998. EOS simulation and GRNN modeling of the constant volume depletion behavior of gas condensate reservoirs, in: SPE Asia Pacific Conference on Integrated Modelling for Asset Management. Society of Petroleum Engineers, Kuala Lumpur. https://doi.org/10.1021/ef970135z

Eslamimanesh, A., Gharagheizi, F., Illbeigi, M., Mohammadi, A.H., Fazlali, A., Richon, D., 2012. Phase equilibrium modeling of clathrate hydrates of methane, carbon dioxide, nitrogen, and hydrogen+water soluble organic promoters using Support Vector Machine algorithm. Fluid Phase Equilib. 316, 34-45. https://doi.org/10.1016/j.fluid.2011.11.029

Eslamimanesh, A., Gharagheizi, F., Mohammadi, A.H., Richon, D., Illbeigi, M., Fazlali, A., Amir, II, Forghani, A., Yazdizadeh, M., 2011. Phase Equilibrium Modeling of Structure $\mathrm{H}$ Clathrate Hydrates of Methane + Water \&quot; Insoluble\&quot; Hydrocarbon Promoter Using Group Contribution-Support Vector Machine Technique. Ind. Eng. Chem. Res 50, 12807-12814. https://doi.org/10.1021/ie2011164

Fazeli, H., Soleimani, R., Ahmadi, M.-A., Badrnezhad, R., Mohammadi, A.H., 2013. Experimental Study and Modeling of Ultrafiltration of Refinery Effluents Using a Hybrid Intelligent Approach. Energy \& Fuels 27, 3523-3537. https://doi.org/10.1021/ef400179b

Fetkovich, M.D., Guerrero, E.T., Of Tulsa, U., Fetkovich, M.J., Thomas, L.K., 1986. SPE Oil and Gas Relative Permeabilities Determined From Rate-Time Performance Data. Society of Petroleum Engineers, New Oreleans. Fevang, Ø., 1995. Gas Condensate Flow Behavior and Sampling. October. 
University of Trondheim.

Fevang, Ø., Whitson, C.H., 1996. Modeling Gas-Condensate Well Deliverability. SPE Reserv. Eng. 11, 221-230. https://doi.org/10.2118/30714-PA

Ghaffari, A., Abdollahi, H., Khoshayand, M.R., Bozchalooi, I.S., Dadgar, A., RafieeTehrani, M., 2006. Performance comparison of neural network training algorithms in modeling of bimodal drug delivery. Int. J. Pharm. 327, 126-138. https://doi.org/10.1016/J.IJPHARM.2006.07.056

Ghahri, P., Jamiolahmady, M., Sohrabi, M., 2011. Gas Condensate Flow Around Deviated And Horizontal Wells, in: SPE EUROPEC/EAGE Annual Conference and Exhibition. Society of Petroleum Engineers, Vienna, pp. 2-23.

Gharagheizi, F., Ilani-Kashkouli, P., Sattari, M., Mohammadi, A.H., Ramjugernath, D., Richon, D., 2014. Development of a LSSVM-GC model for estimating the electrical conductivity of ionic liquids. Chem. Eng. Res. Des. 92, 66-79. https://doi.org/10.1016/J.CHERD.2013.06.015

Ghiasi, M.M., Shahdi, A., Barati, P., Arabloo, M., 2014. Robust modeling approach for estimation of compressibility factor in retrograde gas condensate systems. Ind. Eng. Chem. Res. 53, 12872-12887. https://doi.org/10.1021/ie404269b

Gozalpour, F., Danesh, A., Todd, A.C., Tohidi, B., 2005. Viscosity, density, interfacial tension and compositional data for near critical mixtures of methane + butane and methane + decane systems at 310.95 K. Fluid Phase Equilib. 233, 144150. https://doi.org/10.1016/J.FLUID.2005.03.032

Guo, X., Wang, S., Rong, T., Guo, T., 1997. Viscosity model based on equations of state for hydrocarbon liquids and gases. Fluid Phase Equilib. 139, 405-421. https://doi.org/10.1016/S0378-3812(97)00156-8

Hagan, M.T., Demuth, H.B., Beale, M.H., De Jes s, O., 2014. Neural network design, 2nd ed. Frisco.

Hagan, M.T., Menhaj, M.B., 1994. Training feedforward networks with the Marquardt algorithm. IEEE Trans. Neural Networks 5, 989-993. https://doi.org/10.1109/72.329697

Haykin, S.S., 1994. Neural networks : a comprehensive foundation, 1st ed. Macmillan, New York.

Hemmati-Sarapardeh, A., Shokrollahi, A., Tatar, A., Gharagheizi, F., Mohammadi, A.H., Naseri, A., 2014. Reservoir oil viscosity determination using a rigorous approach. Fuel 116, 39-48. https://doi.org/10.1016/J.FUEL.2013.07.072

Hernandez;, J.C., Vesovic, V., Carter, J.N., Lopez, E., 2002. Sensitivity of Reservoir Simulations to Uncertainties in Viscosity, in: SPE/DOE Improved Oil Recovery Symposium. Society of Petroleum Engineers, Oklahoma, pp. 2-10. https://doi.org/10.2118/75227-ms

Hippert, H.S., Pedreira, C.E., Souza, R.C., 2001. Neural networks for short-term load forecasting : a review and evaluation. IEEE Trans. Power Syst. 16, 4333.

Jalali, farhang, Abdy, Y., Akbari, M., 2007. Dewpoint Pressure Estimation of Gas Condensate Reservoirs, Using Artificial Neural Network (ANN), in: Proceedings of EUROPEC/EAGE Conference and Exhibition. Society of Petroleum Engineers, London. https://doi.org/10.2523/107032-MS

Jokhio, S.A., Tiab, D., Escobar, F., 2002. Forecasting Liquid Condensate and Water Production In Two-Phase And Three-Phase Gas Condensate Systems. Society of Petroleum Engineers, San Antonio, pp. 1-13. https://doi.org/10.2118/77549ms

Jossi, J.A., Stiel, L.I., Thodos, G., 1962. The viscosity of pure substances in the dense gaseous and liquid phases. AIChE J. 8, 59-63. 
Kamari, A., Hemmati-Sarapardeh, A., Mirabbasi, S.-M., Nikookar, M., Mohammadi, A.H., 2013. Prediction of sour gas compressibility factor using an intelligent approach. Fuel Process. Technol. 116, 209-216. https://doi.org/10.1016/J.FUPROC.2013.06.004

Kartoatmodjo, T.R.S., Schmidt, Z., 1991. New Correlations For Crude Oil Physical Properties.

Kashefi, K., Chapoy, A., Bell, K., Tohidi, B., 2013. Viscosity of binary and multicomponent hydrocarbon fluids at high pressure and high temperature conditions: Measurements and predictions. J. Pet. Sci. Eng. 112, 153-160. https://doi.org/10.1016/J.PETROL.2013.10.021

Kay, W.B., 1936. Density of Hydrocarbon. Ind. Eng. Chem. 28, 1014-1019. https://doi.org/10.1021/ie50321a008

Kenneth, L., 1944. A Method for the Solution of Certain Non-Linear Problem in Least Squares. https://doi.org/10.1090/qam/10666

Khan, S.A., Al-Marhoun, M.A., Duffuaa, S.O., Abu-Khamsin, S.A., 1987. Viscosity Correlations for Saudi Arabian Crude Oils, in: Middle East Oil Show. Society of Petroleum Engineers, Bahrain. https://doi.org/10.2118/15720-ms

Khosrojerdi, S., Vakili, M., Yahyaei, M., Kalhor, K., 2016. Thermal conductivity modeling of graphene nanoplatelets/deionized water nanofluid by MLP neural network and theoretical modeling using experimental results. Int. Commun. Heat Mass Transf. 74, 11-17. https://doi.org/10.1016/J.ICHEATMASSTRANSFER.2016.03.010

Lohrenz, J., Bray, B.G., Clark, C.R., 1964. Calculating Viscosities of Reservoir Fluids From Their Compositions. J. Pet. Technol. 16, 1171-1176. https://doi.org/10.2118/915-PA

Mansour, E.M., Farag, A.B., El-Dars, F.S., Desouky, S.M., Batanoni, M.H., Mahmoud, M.R.M., 2013. Predicting PVT properties of Egyptian crude oils by a modified Soave-Redlich-Kowng equation of state. Egypt. J. Pet. 22, 137-148. https://doi.org/10.1016/J.EJPE.2012.09.005

Mesbah, M., Soroush, E., Rostampour Kakroudi, M., 2017. Predicting physical properties (viscosity, density, and refractive index) of ternary systems containing 1-octyl-3-methyl-imidazolium bis(trifluoromethylsulfonyl)imide, esters and alcohols at $298.15 \mathrm{~K}$ and atmospheric pressure, using rigorous classification techniques. J. Mol. Liq. 225, 778-787. https://doi.org/10.1016/J.MOLLIQ.2016.11.004

Mott, R., 2003. Engineering Calculations of Gas-Condensate-Well Productivity. SPE Reserv. Eval. Eng. 6, 298-306. https://doi.org/10.2118/86298-PA

Naderi, M., Khamehchi, E., 2019. Fuzzy logic coupled with exhaustive search algorithm for forecasting of petroleum economic parameters. J. Pet. Sci. Eng. 176, 291-298. https://doi.org/10.1016/J.PETROL.2019.01.049

Nowroozi, S., Ranjbar, M., Hashemipour, H., Schaffie, M., 2009. Development of a neural fuzzy system for advanced prediction of dew point pressure in gas condensate reservoirs. Fuel Process. Technol. 90, 452-457. https://doi.org/10.1016/j.fuproc.2008.11.009

O'Dell, H., Miller, R., 1967. Successfully Cycling a Low-Permeability, High-Yield Gas Condensate Reservoir. J. Pet. Technol. 19, 41-47. https://doi.org/10.2118/1495PA

Pelckmans, K., Suykens, J.A.K., Van Gestel, T., De Brabanter, J., Lukas, L., Hamers, B., De Moor, B., Vandewalle, J., 2002. LS-SVMlab: a MATLAB/C 
Saeedi, J., Rowe, A.M., 1981. Viscosity Correlations for Compositional Reservoir Simulators (SPE9643), in: Middle East Oil Technical Conference of the Society of Petroleum Engineers. Society of Petroleum Engineers, Bahrain, pp. 645-649. https://doi.org/10.2118/9643-MS

Shokir, E.M., 2008. Novel Density and Viscosity Correlations for Gases and Gas Mixtures Containing Hydrocarbon and Non-Hydrocarbon Components. J. Can. Pet. Technol. 47. https://doi.org/10.2118/08-10-45

Soroush, E., Mesbah, M., Shokrollahi, A., Rozyn, J., Lee, M., Kashiwao, T., Bahadori, A., 2015. Evolving a robust modeling tool for prediction of natural gas hydrate formation conditions. J. Unconv. Oil Gas Resour. 12, 45-55. https://doi.org/10.1016/J.JUOGR.2015.09.002

Stiel, L.I., Thodos, G., 1962. The viscosity of polar gases at normal pressures. AIChE J. 8, 229-232. https://doi.org/10.1002/aic.690080220

Suykens, J.A.K., De Brabanter, J., Lukas, L., Vandewalle, J., 2002. Weighted least squares support vector machines: robustness and sparse approximation. Neurocomputing 48, 85-105. https://doi.org/10.1016/S0925-2312(01)00644-0 Suykens, J.A.K., Vandewalle, J., 1999. Least Squares Support Vector Machine Classifiers. Neural Process. Lett. 9, 293-300. https://doi.org/10.1023/A

Thomas, F.B., Bennion, D.B., 2009. Gas Condensate Reservoir Performance. J. Can. Pet. Technol. 10.

Wheaton, R.J., Zhang, H.R., 2007. Condensate Banking Dynamics in Gas Condensate Fields: Compositional Changes and Condensate Accumulation Around Production Wells. https://doi.org/10.2118/62930-ms

Whitson, C., W, J., Brulé, M., 2000. Phase Behavior, 1st ed, Society. Society of Petroleum Engineers. https://doi.org/10.1021/ma00080a014

Whitson, C.H., Fevang, Ø., Yang, T., 1999. Gas Condensate PVT - What's Really Important and Why?, in: Optimisation of Gas Condensate Fields. Norwegian U. of Science and Technology, London. https://doi.org/10.2118/117930-PA

Yang, T., Fevang, O., Christoffersen, K., Ivarrud, E., 2007. LBC Viscosity Modeling of Gas Condensate to Heavy Oil, in: SPE Annual Technical Conference and Exhibition. Society of Petroleum Engineers, Anaheim. https://doi.org/10.2523/109892-ms

Zendehboudi, S., Ali Ahmadi, M., James, L., Chatzis, I., 2012. Prediction of Condensate-to-Gas Ratio for Retrograde Gas Condensate Reservoirs Using Artificial Neural Network with Particle Swarm Optimization. Energy \& Fuels 26, 3432-3447. https://doi.org/10.1021/ef300443j 


\begin{tabular}{|c|c|c|c|c|c|}
\hline Researcher & $\begin{array}{l}\text { Number of data } \\
\text { points }\end{array}$ & Fluid sample & Reported error & Advantages and applicability & Disadvantages \\
\hline $\begin{array}{l}\text { Lohrenz-Bary- } \\
\text { Clark (1964) }\end{array}$ & $\begin{array}{l}520 \text { data points } \\
\text { used to develop } \\
\text { oil viscosity and } \\
300 \text { data samples } \\
\text { used to develop } \\
\text { dense gas } \\
\text { viscosity. }\end{array}$ & $\begin{array}{l}\text { Black to highly } \\
\text { volatile oil } \\
\text { samples. } \\
\text { High pressure } \\
\text { gas mixture. }\end{array}$ & $\begin{array}{l}16 \% \text { of average } \\
\text { error for oil and } \\
4 \% \text { of average } \\
\text { error for gases. }\end{array}$ & $\begin{array}{l}\text { - Can be used to determine both } \\
\text { gas and hydrocarbon liquid } \\
\text { viscosity. } \\
\text { - The LBC correlation uses } \\
\text { reservoir fluid composition to } \\
\text { determine the fluid viscosity. } \\
\text { - Most widely used correlation } \\
\text { due to its simplicity and } \\
\text { flexibility. } \\
\text { - Take account of compositional } \\
\text { changes in reservoirs fluids. }\end{array}$ & $\begin{array}{l}\text { - Very sensitive to mixture density and } \\
\text { critical volume of heavy components. } \\
\text { - Prediction performance of the LBC is } \\
\text { poor for oil viscosity. } \\
\text { - The tuning of coefficients is usually } \\
\text { required to match the experimental data. } \\
\text { - The tuning procedure is not straight } \\
\text { forward especially for gas condensate } \\
\text { fluids. } \\
\text { - Heavy tuning of LBC coefficients can } \\
\text { cause non-monotonic relations between } \\
\text { viscosity and reduced density. }\end{array}$ \\
\hline
\end{tabular}




\begin{tabular}{|c|c|c|c|c|c|}
\hline $\begin{array}{l}\text { Elsharkawy and } \\
\text { Alikhan (1999) }\end{array}$ & $\begin{array}{l}254 \text { crude oil } \\
\text { samples from } \\
\text { Middles East }\end{array}$ & Crude oil & $\begin{array}{l}\text { Average relative } \\
\text { error of } 2.8 \% \text { an } \\
\text { average absolute } \\
\text { error of } 18.6 \% .\end{array}$ & $\begin{array}{l}\text { - Ability to predict the gas- } \\
\text { saturated-oil viscosity in lower } \\
\text { range } 0.05-20.89 \mathrm{cp} \text {. } \\
\text { - Less input parameters in } \\
\text { computation process (API, } \\
\text { reservoir pressure and } \\
\text { reservoir temperature). }\end{array}$ & $\begin{array}{l}\text { - Limited applicability to specific } \\
\text { geographical region. } \\
\text { - } \text { Function of dead oil viscosity, which } \\
\text { reduce the accuracy. } \\
\text { - Require accurate solution gas to oil } \\
\text { ratio. }\end{array}$ \\
\hline $\begin{array}{l}\text { Beggs and } \\
\text { Robinson (1975) }\end{array}$ & $\begin{array}{l}2073 \text { data points } \\
\text { used in } \\
\text { development of } \\
\text { correlation }\end{array}$ & Crude oil & $\begin{array}{l}\text { Average error of - } \\
1.83 \% \text { and } \\
\text { standard } \\
\text { deviation of } \\
27.25 \text {. }\end{array}$ & $\begin{array}{l}\text { - Covers good range of solution } \\
\text { gas to oil ratio (Rs) of } 20- \\
2070 \text { scf/STB. } \\
\text { - Widely used in industry. } \\
\text { - Simple calculation procedure. }\end{array}$ & $\begin{array}{l}\text { - Unknown applicability to the specific } \\
\text { region. } \\
\text { - Unknown ability of predicting different } \\
\text { viscosity ranges. }\end{array}$ \\
\hline
\end{tabular}




\begin{tabular}{|c|c|c|c|c|c|}
\hline $\begin{array}{l}\text { De Ghetto et al. } \\
\text { (1994) }\end{array}$ & $\begin{array}{l}195 \text { oil samples } \\
\text { from } \\
\text { Mediterranean } \\
\text { Basin, Africa, } \\
\text { Persian Gulf, } \\
\text { North America } \\
\text { (3700 data points) }\end{array}$ & $\begin{array}{l}\text { Light crude oil } \\
\text { API > } 31.1\end{array}$ & $\begin{array}{l}\text { Absolute error of } \\
15.2 \% \text { and } \\
\text { standard } \\
\text { deviation of } \\
14.8 \% \text { for oil with } \\
\text { API > } 31.1\end{array}$ & 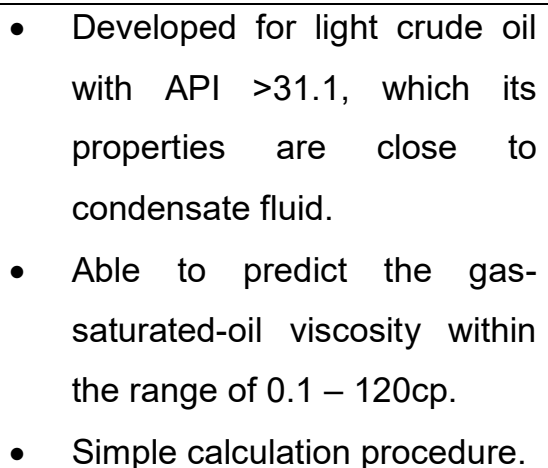 & $\begin{array}{l}\text { - Function of dead oil viscosity, which is } \\
\text { hard to predict accurately. } \\
\text { - Poor performance for predicting of gas } \\
\text { condensate reservoirs. }\end{array}$ \\
\hline
\end{tabular}


817 This section covers mathematical hypothesis of simple neural network architecture

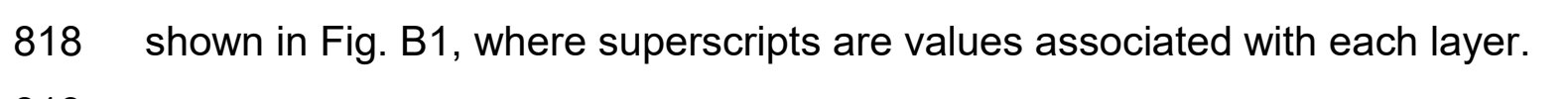
818 shown in Fig. B1, where superscripts are values associated with each layer.

819 (1)

\section{2}

823

824

825

826

$$
a i^{(j)}=\text { activation" of unit } i \text { in layer } j
$$

827 In order to calculate each activation function $(a)$ a sigmoid function $(g)$ is multiplied by

$\theta^{(j)}=$ matrix of weights controlling function mapping from layer $j$ to layer $j+1$ 828 sum of linear combination of inputs for each neuron; these inputs include $829\left(x_{1}, x_{2}, x_{3}\right.$ and bias unit $\left.x_{0}\right)$ in hidden layer. Eq. (B1) to Eq. (B3) are representing the 830 calculation of the activation functions.

831 Then the output function $h_{\theta}(x)$ shown in Eq. (B4) is a sigmoid function of sum of each 832 neuron's weight multiplied by activation function of same neuron in layer 2 . The 833 neurons of the output layer have linear transfer functions.

$834 a_{1}^{(2)}=g\left(\Theta_{10}^{(1)} x_{0}+\Theta_{11}^{(1)} x_{1}+\Theta_{12}^{(1)} x_{2}+\theta_{13}^{(1)} x_{3}\right)$

$835 a_{2}^{(2)}=g\left(\theta_{20}^{(1)} x_{0}+\theta_{21}^{(1)} x_{1}+\theta_{22}^{(1)} x_{2}+\theta_{23}^{(1)} x_{3}\right)$

836

$$
a_{3}^{(2)}=g\left(\theta_{30}^{(1)} x_{0}+\theta_{31}^{(1)} x_{1}+\theta_{32}^{(1)} x_{2}+\theta_{33}^{(1)} x_{3}\right)
$$

$837 h_{\theta}(x)=a_{1}^{(3)}=g\left(\Theta_{10}^{(2)} a_{0}^{(2)}+\theta_{11}^{(2)} a_{1}^{(2)}+\theta_{12}^{(2)} a_{2}^{(2)}+\theta_{13}^{(2)} a_{3}^{(2)}\right)$

838 In above equation $g$ is a sigmoid type function and can be evaluated from Eq. (B5).

$839 g(z)=\frac{1}{\left(1+e^{-z}\right)}$ 
840 To vectorise the above mathematical definition of neural network presented in 841 Equation (B1) to (B3), the following relations can be defined:

842 If:

843

$\left\{\begin{array}{c}\theta_{10}^{(1)} x_{0}+\theta_{11}^{(1)} x_{1}+\theta_{12}^{(1)} x_{2}+\theta_{13}^{(1)} x_{3}=Z_{1}^{(2)} \\ \theta_{20}^{(1)} x_{0}+\theta_{21}^{(1)} x_{1}+\theta_{22}^{(1)} x_{2}+\theta_{23}^{(1)} x_{3}=Z_{2}^{(2)} \\ \theta_{30}^{(1)} x_{0}+\theta_{31}^{(1)} x_{1}+\theta_{32}^{(1)} x_{2}+\theta_{33}^{(1)} x_{3}=Z_{3}^{(2)}\end{array}\right\}$

844

845 Substituting Equation (B6) into Eq. (B1) to Eq. (B3) defines the activation functions in 846 Equation (B7).

847

$$
\left\{\begin{array}{l}
a_{1}^{(2)}=g\left(Z_{1}^{(2)}\right) \\
a_{2}^{(2)}=g\left(Z_{2}^{(2)}\right) \\
a_{3}^{(2)}=g\left(Z_{3}^{(2)}\right)
\end{array}\right\}
$$

848

849 And If:

850

$$
\left\{\begin{array}{c}
x=\left[\begin{array}{l}
x_{0} \\
x_{1} \\
x_{2} \\
x_{3}
\end{array}\right] \\
Z^{(2)}=\left[\begin{array}{l}
Z_{1}^{(2)} \\
Z_{2}^{(2)} \\
Z_{3}^{(2)}
\end{array}\right]
\end{array}\right\}
$$

851 And then input functions substitute with $a^{(1)}$ in layer one:

852

$$
\left\{\begin{array}{c}
Z^{(2)}=\Theta^{(1)} x=\theta^{(1)} a^{(1)} \\
a^{(2)}=g\left(Z^{(2)}\right)
\end{array}\right\}
$$

853 In equation $\mathrm{B} 9, a^{(2)}$ is [3×3] matrix without bias function, and if $a_{0}^{2}=1$ for bias unit in 854 layer $2, Z^{(3)}$ defined as follow:

$855 Z^{(3)}=\theta^{(2)} a^{(2)}$

856 The value of the final function or output layer is sigmoid function of $Z^{(3)}$, as shown in 857 Eq. (B11).

$858 h_{\theta}(x)=g\left(Z^{(3)}\right)$

The values of $x$ are considered as input of activation function. The above calculation 861 was carried out and completed in MATLAB, to determine the output values. 